\title{
Early history of sudden commencement investigation and some newly discovered historical facts
}

\author{
Yasuharu Sano ${ }^{1}$ and Hiroshi Nagano ${ }^{2, \text {, }}$ \\ ${ }^{1}$ School of Business Administration, Asahi University, Mizuho 501-0296, Japan \\ ${ }^{2}$ School of Dentistry, Asahi University, Mizuho 501-0296, Japan \\ ¿retired \\ Correspondence: Yasuharu Sano (sanoo@alice.asahi-u.ac.jp)
}

Received: 18 May 2021 - Revised: 10 August 2021 - Accepted: 19 August 2021 - Published: 15 September 2021

\begin{abstract}
The history of the research on the SC (sudden commencement) of magnetic storms before World War II is studied in this paper. Since geomagnetic research activities before World War II are still not yet fully known, this paper aims to reveal some historical facts related to SC investigation at that time. The first conclusion of this paper is the possible first discoverer of the simultaneity of SC at distant locations. We show that a Portuguese scientist had already pointed it out 16 years earlier than believed. The second conclusion is the role and activities of Aikitu Tanakadate as the reporter of the SC investigation committee of STME (Section of Terrestrial Magnetism and Electricity) and IATME (International Association of Terrestrial Magnetism and Electricity) in the IGGU (International Geodetic and Geophysical Union) or IUGG (International Union of Geodesy and Geophysics). Very little was known about his activities as the reporter of this committee. Our investigation at the Tanakadate Aikitu Memorial Science Museum disclosed how he acted and what he thought of SC, based on his frequent letters to and from other scientists. The third conclusion concerns SC research carried out by Japanese scientists during the period of the Second International Polar Year (1932-1933). Not only Tanakadate but also many other Japanese scientists participated in SC research during this international project. This formed a traditional basis of SC investigation in Japan, prompting a number of Japanese scientists to study SC after World War II.
\end{abstract}

\section{Introduction}

Magnetic storms usually begin with sudden increase in the geomagnetic horizontal component. This phenomenon is called a sudden commencement (often abbreviated to SC) of magnetic storm. A question was raised, and had long been discussed, as to whether the timing of an SC breakout can be regarded as simultaneous all over the world.

The mechanism of SC is very clearly understood at present. It is caused by a sudden compression of the magnetosphere due to the arrival of interplanetary shockwave or discontinuity in the solar wind emitted from the Sun when a flare, CME (coronal mass ejection) and/or CIR (co-rotating interaction region) occurs or appears on its surface (Araki, 1994; Gosling and Pizzo, 1999). However, it was really difficult for the scientists in the past to understand this enigmatic phenomenon, as they had no way of knowing about the existence of solar wind or magnetosphere. They thought that identifying the time difference of an SC onset at various places on the Earth would give a clue to solve the mystery of geomagnetism (Chree, 1910).

Historically speaking, existence of SC was discovered first (Brooke, 1847a, b), its simultaneity was then questioned (Capello and Stewart, 1864; Adams, 1880; Ellis, 1880) and a propagation hypothesis was submitted by Bauer (1910a), while Charles Chree and others preferred the simultaneity hypothesis (Chree, 1910, 1911). For the purpose of elucidating the SC problem, an international committee was created in the Section of Terrestrial Magnetism and Electricity under the International Geodetic and Geophysical Union. Aikitu Tanakadate from Japan was appointed as the reporter of this committee to promote studies on SC. However, the problem was not solved despite the efforts of Tanakadate, Bauer, Chree and many other scientists. 
After deaths of Bauer and Chree, Tanakadate decided to settle this problem by himself. He planned more detailed observations in the Japanese territory during the Second International Polar Year (1932-1933). Several Japanese scientists, such as Shuiti Imamiti, Hisanao Hatakeyama, Suminosuke Ono, Takematsu Okada and Hantaro Nagaoka participated in those observations (Imamiti, 1938; Ono, 1934a, b).

Their work constructed a traditional basis of SC investigation in Japan. This tradition can be seen in the fact that many Japanese geomagnetic researchers studied SC after World War II and contributed to the development of geomagnetism. In this sense, studying the history of SC investigation before the end of World War II seems to be important for understanding the whole history of geomagnetism.

We investigated old materials, including those preserved in the Tanakadate Aikitu Memorial Science Museum in Ninohe, Iwate, Japan, and found several newly discovered historical facts on the studies of SC. From these results, we can infer what was going on and what the scientists of the era, without the concept of magnetosphere and solar wind, were thinking about SC.

\section{Before discovery of the SC (sudden commencement) of magnetic storms (1842)}

\subsection{Discovery of geomagnetic secular variation}

Before proceeding with the discovery of the sudden commencement of magnetic storms, let us first start with a quick look at the discovery of geomagnetic secular variation, diurnal variation and magnetic storms.

William Gilbert (1544-1603; also spelled Gilberd, Gilberde or Gylberde), one of the own physicians of Queen Elizabeth I and also a scientist in the field of physics, astronomy and philosophy, first pointed out that our Earth could be a giant magnet. He concluded this from several experiments using a magnetic ball imitating the Earth (which was named Terrella). To publish his opinion, he wrote a book $D e$ Magnete, Magneticisque Corporibus, et de Magno Magnete Tellure (On the Loadstone and Magnetic Bodies and on the Great Magnet the Earth) in Latin in 1600. As a result of this very famous book, Gilbert is now often called a pioneer in the field of the scientific research of geomagnetism.

A total of 35 years after the publication of Gilbert's book, the existence of geomagnetic secular variation, that is to say that the declination angle of the Earth's magnetic field from the geographical true north at one observation point is not a constant but can vary gradually over time, was discovered by Henry Gellibrand (1597-1637 (or 1636)) in 1634 (or 1633; Chapman and Bartels, 1940, p. 910). The value of the declination angle in London that Gellibrand observed was different to the values reported by Burrows in 1580 and by Gunter in 1622. The result seemed to show that the geomagnetic declination angle in London had slowly changed in value with the progress of time. He wrote a book named $A$ dis- course mathematical on the variation of the magneticall needle Together with its admirable diminution lately discovered in 1635 to publish his findings.

Gellibrand's conclusion had a tremendous impact on the people because magnetic charts used for navigation must be renewed periodically if geomagnetic declination values really vary over time. Scientists were also very astonished at why and how geomagnetism could change with time because only permanent magnets were known as the source of magnetism at that time.

British astronomer Edmond Halley (1656-1742), well known for predicting the recursion of a comet, attempted to set up a double-layered crust model in order to explain the secular variation in the geomagnetic field observed on the Earth. According to his theory, the Earth's interior is composed of magnetized outer spherical layer and inner core slipping between them. He proclaimed that relative motions of those magnetized layers and the core could produce the time-changing magnetic field observed on the Earth (Halley, 1692).

\subsection{Discovery of geomagnetic diurnal variation}

George Graham (1675 (1673 or 1674)-1751) was a British clock engineer. He observed the direction of a $12 \mathrm{in.}$ $(30.48 \mathrm{~cm})$ long bar magnet in London more than 1000 times and noticed that there existed small deflections in the direction of his bar magnet in a day (Malin, 1987). The bar magnet exhibited a very regular pattern of deflection every day, although its amplitude was as small as 2 arcmin in angle (Graham, 1724). This type of daily regular change is called geomagnetic diurnal variation at present.

\subsection{Discovery of geomagnetic disturbance}

Graham also found the existence of irregular changes in addition to the regular daily variations. Those irregular variations often lasted for several hours, and the amplitude sometimes reached as large as 30 arcmin in angle (Fig. 1).

Swedish astronomer Anders Celsius (1701-1744) and his assistant Olof Hiorter (1696?-1750) made a number of aurora observations at Uppsala. They questioned whether the geomagnetic disturbances that Graham reported would take place over a wide area on the Earth. They proposed a simultaneous observation in both Uppsala and London to Graham. Celsius' hypothesis was confirmed by a simultaneous observation of geomagnetic disturbances in both Uppsala and London when a low-latitude aurora appeared on 5 April 1741 (Chapman and Bartels, 1940, p. 923; Malin, 1987).

A very sensitive device for measuring the strength of force was invented by French physicist Charles Augustin de Coulomb (1736-1806). This device, called a torsion balance, was used to experimentally derive Coulomb's law in 1785. It had a structure of a small metal plate suspended by a fine silk fiber. Torsion balance was also soon applied to measuring ge- 
April 15.1723.

\begin{tabular}{|c|c|}
\hline $4^{\circ}=30^{\prime}-$ & $9^{h}=00$ \\
\hline $14=30$ & $10=\infty$ \\
\hline$=30$ & $\mathbf{I}=30$ \\
\hline$=30+$ & $\mathbf{r} 2=30$ \\
\hline$=30+$ & $\mathbf{I}=30$ \\
\hline 30 & $3=30$ \\
\hline$=30$ & $4=10$ \\
\hline 30 & $5=30$ \\
\hline 20 & $6=18$ \\
\hline 4 & $7=8$ \\
\hline$\infty$ & $7=50$ \\
\hline 00 & $8=15$ \\
\hline$\times 5$ & $8=20$ \\
\hline 15 & $8=4^{\circ}$ \\
\hline 5 & $12=15$ \\
\hline & $\mathbf{r}_{2}=27$ \\
\hline & $r_{2}=32$ \\
\hline & $x_{2}=3$ \\
\hline & $2=$ \\
\hline
\end{tabular}

Wind at S. W.

Figure 1. An example of Graham's observation when a large disturbance occurred. The left column shows the geomagnetic declination angles he observed, and the right column shows the time of the observation (Graham, 1724).

omagnetic force, bringing about a significant improvement in the accuracy of data compared to data obtained from observations using a compass with pivoting magnetic needle.

It can be said that this apparatus was a very primitive type of magnetometer capable of measuring the horizontal force and the declination angle of geomagnetic field. On the other hand, the inclination angle of a geomagnetic field can be measured by another type of magnetometer, i.e., by a dip circle, which has a structure of gravitationally balanced magnetic needle being able to rotate freely in the vertical plane.

\subsection{Humboldt's geomagnetic observations}

Alexander von Humboldt (1769-1859) is a prominent German geographer. Being deeply interested in geomagnetism, he made geomagnetic observations using a portable dip circle in many places that he visited on his travels around the world. During his travels in South America, not only did he observe the inclination angles by his dip circle, but also he estimated the strength of geomagnetic total force by letting the magnet on the dip circle slightly oscillate around its equilibrium (Malin and Barraclough, 1991). The oscillation period was shorter in high latitudes than in equatorial region, which meant that the geomagnetic total force became larger with increasing latitude. He is thought to be the first who tried to investigate the spatial distribution of geomagnetic total force in the world.

After returning to Europe, Humboldt recorded geomagnetic variations every $30 \mathrm{~min}$ for the period of from May 1806 to July 1807. Humboldt is also known for using the nomenclature of "magnetic storm" to describe large irregular geomagnetic fluctuations.

\subsection{Gauss' achievements and geomagnetic variations with their source outside the Earth}

Carl Friedrich Gauss (1777-1855), a very famous German mathematician and astronomer with conspicuously outstanding talent, was one of the acquaintances of Humboldt. When he met Humboldt in Berlin in 1928, he was strongly invited by Humboldt to join geomagnetic studies. On the advice of Humboldt, he started his geomagnetic research with his colleague, Wilhelm Eduard Weber (1804-1891) from around 1831 .

In 1832, Gauss invented the first method in the world to measure the absolute strength of geomagnetic field (Chapman and Bartels, 1940, p. 35, p. 927). This is a method consisting of two experiments called the oscillation experiment and deflection experiment. The product and division of the horizontal intensity of the geomagnetic field and the magnetic moment of the magnet used can respectively be determined from these two experiments. If the moment of inertia of the magnet is already known, one can obtain the absolute value of the geomagnetic horizontal force which, together with the value of inclination angle, can give the total geomagnetic force.

In 1833, Gauss built a magnetic observatory in Göttingen to monitor geomagnetic field. After that, number of magnetic observatories increased, leading to the establishment of the Göttingen Magnetic Union under the leadership of Gauss in 1836. In addition, Humboldt also assisted Gauss by directly proposing to British and Russian governments that they construct geomagnetic observatories in various areas across the world because the United Kingdom had colonies worldwide and Russia had a large territory.

Using these worldwide data, Gauss succeeded in expressing geomagnetic potential as a series of spherical harmonic functions and the negative powers of the distance form the center of the Earth (Chapman and Bartels, 1940, p. 606). From this, Gauss concluded that most of the source producing the geomagnetic field lay inside the Earth, while not excluding the possibility that the residual small portion, especially the variations with a short time period, arose from a source above the ground (Glassmeier and Tsurutani, 2014). Thus, Gauss suggested the existence of geomagnetic variations with its source outside the Earth. 


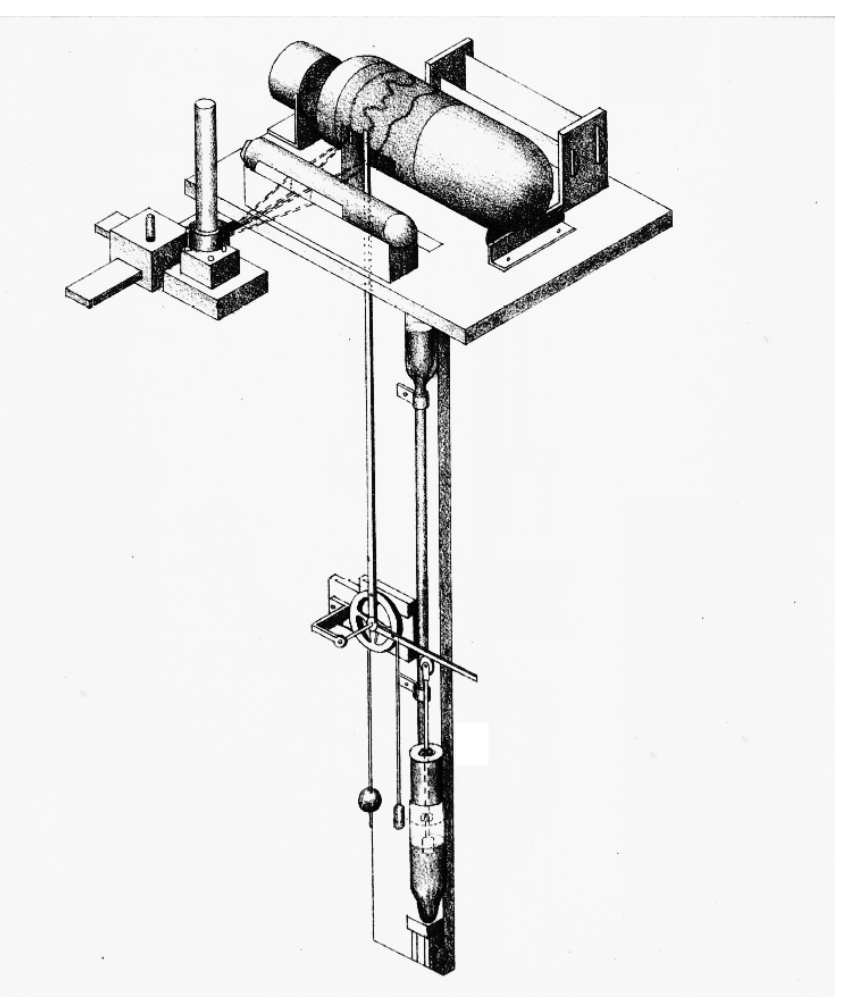

Figure 2. Sketch of the automatic registration system invented by Brooke (1847b).

\section{Discovery of SC (sudden commencements) of magnetic storms (1843-1923)}

\subsection{Invention of the automatic recorder}

Steady observations of the geomagnetic field began at Kew Observatory in London in 1818. This was a repeated eye observation at scheduled observation times. Same-style observations started at Greenwich and at Paris in 1820, at Chennai in 1822 and also at other observatories in the world.

George Biddell Airy (1801-1892), also known for his theory of isostasis on the gravity equilibrium of the Earth's crust, was the director of the Greenwich Observatory at London, i.e., he was the seventh Astronomer Royal of the United Kingdom from 1835 to 1881 . As will be stated below, Greenwich Observatory was the first to introduce an automatic recording system for the observation of geomagnetic field variation (Airy, 1886). Airy and Charles Brooke (1804-1879), a surgeon and also an inventor, tried to adopt a photographic self-recorder invented by Brooke himself. This recorder had a small bar magnet equipped with a tiny mirror suspended by a spider silk. Light from a small lamp behind a thin slit was reflected by the mirror so as to draw a trajectory on a sheet of photographic paper placed on a cylinder rotating once a day (Fig. 2).

Brooke's paper on his self-recording system used at Greenwich Observatory was submitted to volume 5 of $A b$ - stracts of Papers Communicated to the Royal Society of London on the recommendation of Airy (Brooke, 1843a, b). Volume 5 of this journal is a joint volume for the papers submitted between 1843 and 1850, although the year of publication is simply denoted as 1843. Brooke's paper was submitted in November 1846, in which Brooke states that he presented an oral report on his self-recording system in June 1846. From these records, we can confirm that Brooke's self-recording system was presumably adopted at Greenwich Observatory in 1846. More detailed architecture of his self-recording system and examples of recorded magnetogram can be found in volume 137 of Philosophical Transaction of Royal Society of London (Brooke, 1847a, b).

Francis Ronalds (1788-1873), director of the Kew Observatory, also invented a similar instrument for automatic recording. Ronalds' papers are published in the same volumes, that is, in volume 5 of Abstracts of Papers Communicated to the Royal Society of London (Ronalds, 1843), and in volume 137 of Philosophical Transaction of Royal Society of London (Ronalds, 1847). Thus, Kew Observatory also introduced an automatic recording instrument independently of Greenwich Observatory almost at the same time. Ronalds, however, did not show any magnetogram of his apparatus in his paper.

Automatic recording systems were gradually adopted at various geomagnetic observatories all over the world for its advantage over eye observations.

\subsection{Discovery of SC}

The fact that magnetic storms often begin with a very rapid increase in the horizontal component of geomagnetic field may probably be known qualitatively from the period of eye observation. However, quantitative discussions appeared only after the introduction of the self-recording system stated in the previous section.

Brooke and Airy seem to have already noticed existence of such geomagnetic fluctuations that appeared at the beginning of magnetic storms because they state it in their paper: "Plate VII (Fig. 9). The commencement of the magnetic storm of 5 September 1896. The oil lamp was in use, and this shows its inability to impress the photographic paper during rapid movements of the magnet when the registration is most important" (Brooke, 1847a, b). Unfortunately, as they themselves also write, the magnetogram they showed is an example of a failed observation in which they tried to record a rapid variation at the beginning of magnetic storm, and therefore, no variations in the horizontal force resembling an SC can be seen on the magnetogram in the paper.

Magnetograms shown in these papers are those of magnetic storms that occurred in 1846. We suspect from this that it is very probable that Brooke and Airy would have been the first to discover the SC phenomenon by using magnetograms. However, this can merely be considered as an indirect evidence-based assumption, since Brooke simply wrote 


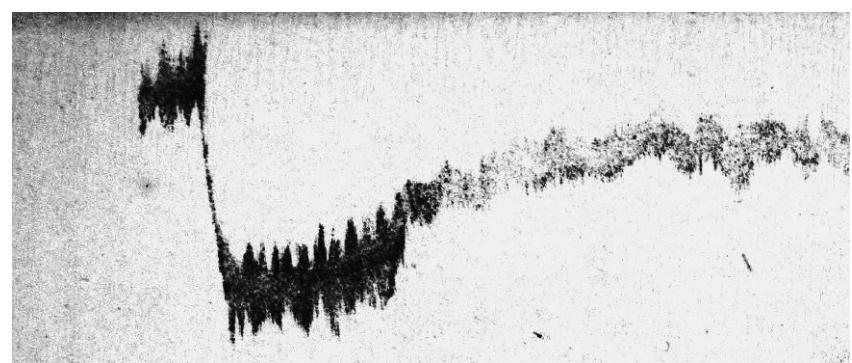

Figure 3. Example of a magnetic shock reported by Brooke (1847b).

that there was a rapid change in the horizontal force when a magnetic storm occurred, giving no magnetograms that record a sudden change like an SC (due to a failure in recording, according to Brooke).

Brooke also refers to existence of another kind of sudden change in the declination angle of geomagnetic field which he called a "magnetic shock". This magnetic shock given in Brooke's paper looks similar to an SC, although there is a difference in that it appears in the $D$ component (Fig. 3).

\subsection{Discovery of simultaneity of SC}

What will be discussed on when we talk about "simultaneity of SC" may usually be the problem of whether or not the starting time of a magnetic storm can be regarded as simultaneous everywhere on Earth.

It has long been said that William Grylls Adams (18361915) and William Ellis (1828-1916) were, in 1880, the first to discover the simultaneity of SC by comparing magnetograms recorded at different places (Adams, 1880; Ellis, 1880). However, our investigation revealed that the simultaneity of SC had already been reported by a Portuguese naval officer and meteorologist João Carlos de Brito Capello (1831-1901) in 1864 (Capello and Stewart, 1864), 16 years earlier than the papers of Adams and Ellis.

Capello was an observer at Dom Luiz Observatory in Lisbon (Lisbon Observatory). He went to Kew Observatory in London and learned how to manipulate a Kew pattern magnetometer with Balfour Stewart (1828-1887), director of Kew Observatory, because the Dom Luiz Observatory had bought a Kew pattern magnetometer from ADIE \& CO LTD in the United Kingdom. After Capello's return to Lisbon, the Dom Luiz Observatory began its continuous magnetic observation in 1863 (Bonifácio et al., 2007).

On 15 July 1863, the Kew pattern magnetometer at the Dom Luiz Observatory caught a magnetic storm at Lisbon. Capello asked Stewart to send a magnetogram of this magnetic storm at Kew Observatory to compare it with his data. In his paper, Capello describes it clearly: "The disturbance, as shown by the Kew curves, commenced on July 15th, at 9h13m.5 G.M.T., at which moment the horizontal force curve recorded an abrupt augmentation of force", and "A great dis-

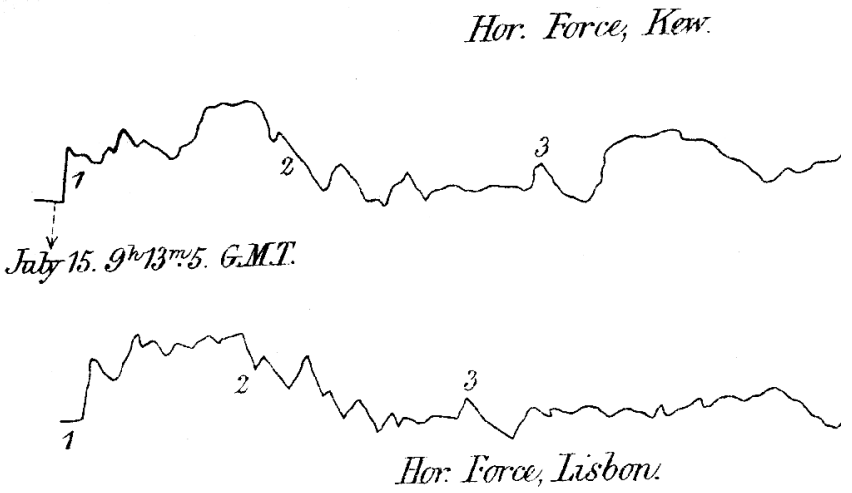

Figure 4. An SC recorded simultaneously at Kew (top) and at Lisbon (bottom) on 15 July 1863. Numbers 1, 2 and 3 denote, respectively, the same instance. Time duration between numbers 1 and 3 is about $2 \mathrm{~h} 40 \mathrm{~min}$ (after Capello and Stewart, 1863).

turbance, which at $8 \mathrm{~h} 37 \mathrm{~m}$ Lisbon mean time, or $9 \mathrm{~h} 13 \mathrm{~min} 5$ Greenwich mean time, abruptly and suddenly augmented the horizontal force" (Fig. 4). As far as the authors have investigated, this is the earliest description to state that the sudden enhancement in the strength of horizontal component of geomagnetic field accompanying the beginning of a magnetic storm occurred simultaneously at two remote stations. When a magnetic storm begins, such a sudden enhancement of the horizontal component is often recorded on the magnetogram in such a way that a stepwise variation in the horizontal component took place, as can be seen in the magnetograms given in Capello's paper. We therefore infer that Capello should be the first ever, at the present stage, to discover the simultaneity of SC by comparing magnetograms at two different places.

Capello's discovery was soon communicated to Stewart in London and was published in volume 13 of Proceedings of Royal Society of London. This volume is, although denoted as being issued in 1863 , was in fact published in 1864 for some reason.

However, the society at that time does not seem to have paid much attention to Capello's discovery. Neither Adams nor Ellis cited Capello's paper when they approached the same problem again in 1880. As a result, Capello's achievement was completely forgotten in history because later scientists could not reach Capello's paper by tracing the references.

A total of 16 years after Capello's discovery, Adams, a professor at King's College in London, analyzed several magnetic storms that occurred in March 1879 (Adams, 1880). Comparing the $D$ components of geomagnetic field at six stations, i.e., Kew, Stonyhurst, Coimbra, Lisbon, Vienna and St. Petersburg, he pointed out some similarities between the magnetograms at those stations. He also suggested in this paper that a disturbance in the Earth current might be the cause of geomagnetic storms. 
Ellis, a British astronomer and meteorologist in Greenwich, discussed the problem more clearly than Adams did, although this paper is much more concise than Adams' (Ellis, 1880). He compared $H$ and $D$ components of two magnetic storms on 11 and 18 August 1880 in Greenwich and in $\mathrm{Zi}-\mathrm{Ka}$-Wei (in Shanghai). Ellis writes that these magnetic storms began with a "sharp increase of horizontal force" almost at the same time in Greenwich and $\mathrm{Zi}-\mathrm{Ka}$-Wei. It should be noted here that simultaneity of SC at two distant locations (namely London and Shanghai) was first reported by Ellis, while Capello and Adams only discussed the stations in Europe. The following year, Adams also discussed on SC simultaneity at distant stations (Adams, 1881) in which he wrote "a sudden considerable increase in the horizontal force" and "The storm begins at the same instance in Europe, Asia, and America, in high northern and southern latitudes, and also near the Equator".

Ellis published his next paper in 1892. In this paper, Ellis analyzed the onset times of several magnetic storms occurring between April 1880 and September 1889. He concluded that there might exist a time lag from +2.4 to $-2.9 \mathrm{~min}$ in the onset times, although it was still not certain if these were real phenomena or simply observational errors. Adams also wrote a paper on magnetic storms in the same year (1892). Historical facts on SC research by Adams and Ellis are also discussed by J. J. Curto, T. Araki and L. F. Alberca (Curto et al., 2007).

It would be noteworthy to look here at the reason why the problem of the simultaneity of SC interested the scientists at that time. A set of fundamental equations for the electromagnetic field was derived by James Clerk Maxwell (18311879 ) in 1864, with a prediction of electromagnetic waves which can propagate in a vacuum space with the speed of light. However, the existence of electromagnetic waves was not readily proved after Maxwell's prediction; it was proved by Heinrich Rudolf Hertz (1857-1894), who performed a ring coil experiment in 1887 (published in 1888). Thus, the existence of the electromagnetic wave was still a hypothesis when Ellis found the simultaneity of SC in London and Shanghai in 1880. Scientists debated whether this phenomenon was related to the electromagnetic waves predicted by Maxwell.

\subsection{Bauer's SC propagation hypothesis}

In 1910, a paper titled "Beginning and propagation of magnetic disturbance of May 8, 1902, and of some other magnetic storms" (Bauer, 1910a) was presented by Louis Agricola Bauer (1865-1932), who was in position of the head researcher at the Carnegie Institution of Washington.

Bauer was born in Cincinnati, Ohio, in 1865. He became an assistant at the United States Coast and Geodetic Survey after graduating from Cincinnati University. From 1892, he went to Germany and studied geomagnetism for 3 years at the University of Berlin and also at Potsdam Magnetic Ob- servatory. Returning to the United States after obtaining his doctorate in Germany, Bauer taught at Chicago University and at Cincinnati University while studying geomagnetism at the United States Coast and Geodetic Survey. He also created a journal entitled Terrestrial Magnetism in 1896 (this journal was later renamed Terrestrial Magnetism and Atmospheric Electricity. It was merged with other journals to be integrated into Journal of Geophysical Research after World War II). In 1904, Bauer was invited to the Department of Terrestrial Magnetism of the Carnegie Institution of Washington where he became the chief researcher. This nonprofit institution was established by the Carnegie Foundation with the aim of making purely scientific contributions.

Bauer's paper mentioned above appeared in volume 15 of Terrestrial Magnetism and Atmospheric Electricity. His paper triggered a series of heated discussions among scientists on the problem of the simultaneity of SC. It was in a subsequent paper in which Bauer (1902) reported that an SC occurred 2 min after a large volcanic eruption of Mount Pelée on Martinique island in the Caribbean. From this, Bauer thought of a hypothesis that argued that a volcanic eruption might induce a magnetic storm. If this is the case, a magnetic storm should propagate concentrically like a seismic wave that propagates in all directions from the epicenter. And if this is so, then its onset time should vary from place to place.

Hence, Bauer (1910a) tried to investigate the time difference of SC in his paper. He selected the magnetic storm of 8 May 1902 and analyzed its onset time at 25 geomagnetic stations, the data of which had been supplied to Bauer by Robert Lee Faris (1862-1932) of the United States Coast and Geodetic Survey. Based on this analysis, Bauer proclaimed that magnetic storms propagated mainly westward (but in some cases eastward), with a velocity of about $180 \mathrm{~km} \mathrm{~s}^{-1}$, suggesting that a magnetic storm may take about 3.5 to $4 \mathrm{~min}$ to propagate around the Earth.

Although there were no volcanic eruptions found on the Earth before the occurrence of this magnetic storm, Bauer firmly believed that there should exist some kind of triggering event, instead of a volcanic eruption, that allowed the magnetic storm to occur.

Bauer and Faris published a series of papers in order to quantitatively determine the propagation speed of SC (Bauer, 1910b, c, d; Faris, 1910). All those papers suggested a propagation speed between 90 and $200 \mathrm{~km} \mathrm{~s}^{-1}$.

In addition, Bauer proposed an ion current theory of geomagnetic disturbances. According to his theory, there is an ion flow in the electroconductive layer above the ground. This ion flow can move with an average velocity of $181 \mathrm{~km} \mathrm{~s}^{-1}$ after some triggering event. Bauer was quite confident of his theory, which he thought to be a possible explanation of the onset time difference of SC observed by himself and Faris. 


\subsection{Criticism by other scientists}

Those papers that Bauer submitted with strong confidence were met with criticism from a number of scientists. Ole Andreas Krogness (1886-1934) in Norway questioned the time accuracy given by Bauer and Faris in their papers, stating that they did not explain how the observation times at different stations were compared and calibrated mutually (Krogness, 1910). Krogness also suggested that technical improvements would be necessary to determine the time differences accurately if one wanted to discuss the theory in more detail.

Charles Chree (1860-1928) in the United Kingdom also supported Krogness' opinion (Chree, 1910). Chree showed three types of possibilities, namely that (a) SCs are absolutely simultaneous at every different observational point, (b) there is a very slight difference in time from place to place corresponding to the propagation time of electromagnetic waves and (c) there is a time difference of several minutes from one place to another place on the Earth, as Bauer proclaims. He also noted that point (c) and others should be distinguishable even at present, although the distinction between points (a) and (b) would go far beyond the present technique. Chree also pointed out the insufficiency of Faris' results to give a proof to Bauer's theory and proposed a systematic comparison of time differences, carefully selecting trustable observatories, since the time differences shown by Faris might have occurred due to instrumental or observational errors.

As far as the authors have investigated, the term "sudden commencement" was first used in 1906 by Willem van Bemmelen (1868-1941) at Batavia Observatory in the Dutch East Indies in order to refer to the beginning of magnetic storms (van Bemmelen, 1906). Whether this term is of van Bemmelen's own creation is not clear, as he wrote nothing about its naming in his paper. This term was then next used in the above paper of Chree (1910), in which Chree writes expressly that there are "so-called "sudden commencements"; from what we know, in 1910 this term was already used by several scientists along with van Bemmelen. There would surely be no need to give a proper name to the sudden beginning of magnetic storms before Bauer raised the question of non-simultaneity of SCs in 1910. After the submission of Bauer's question, scientists realized the need for a specific technical term to denominate this phenomenon. For this reason, Chree proposed the expression of sudden commencement as an official technical term, expecting that this term be widely accepted. After this, most of the scientists agreed with Chree and used sudden commencement to describe this phenomenon, while Bauer persisted in using a different term, i.e., "abruptly beginning magnetic disturbance" throughout his life (see, e.g., Bauer and Peters, 1925).

Bauer soon wrote two papers (Bauer, 1911a, b) in which he contradicted Krogness and Chree, insisting that the time at Potsdam that Krogness read from magnetogram was incorrect and that Chree misunderstood Bauer's SC propagation theory.
Garmt van Dijk (1877-1940) in Holland criticized Bauer's papers, giving a more detailed discussion on determining the onset time of SCs (van Dijk, 1911). Chree also published a paper of a similar discussion (Chree, 1911). Faris soon published a paper defending Bauer (Faris, 1911a), but this led to Birkeland (1867-1917) writing two more papers favoring Chree (Birkeland, 1911a, b).

\subsection{Continuation of discussion}

Bauer proposed the next method to settle the problem, as a number of papers criticizing each other appeared in a short period of only about 1 year. He proposed selecting reliable observatories and asking them to determine the onset time of SCs from a neutral standpoint.

In total, 17 reliable observatories were selected by Bauer and Faris to accurately determine the onset times of 15 SC events (Bauer, 1911c). More observatories were added later, amounting to a total of 32 observatories (Bauer, 1911d). Bauer and Faris insisted repeatedly that the non-simultaneity of SC was surely confirmed by using data from these observatories (Bauer, 1911b; Faris, 1911b).

However, not only Chree but also Gustav Heinrich Angenheister (1878-1945), Sydney Chapman (1888-1970) and Societas Jesu Reverend Lluís Rodés Campderà (1881-1939) voiced objections against the papers of Bauer and Faris. Angenheister at Apia Observatory in Samoa proclaimed that there did not seem to exist any time differences larger than the observational errors of normal run magnetographs (Angenheister, 1913). Chree also published a paper in which he mentioned almost the same results as those of Angenheister (Chree, 1914). In this paper, Chree first pointed out the importance of standardization in observation instruments, as various types of magnetometers, such as Kew pattern, Mascart type, Eschenhagen type and others, were under use.

Chapman in the United Kingdom obtained the value of less than $30 \mathrm{~s}$ for the time difference of SC occurrence based on the ion flow theory that Edward Walter Maunder (18511928) proposed in 1905 and denied the time difference of several minutes that Bauer and Faris insisted on (Chapman, 1918). Angenheister again wrote an article in which he obtained an upper limit of several seconds as the time difference of SC onset (Angenheister, 1920). Rodés at Ebro Observatory in Spain also published a paper of almost the same conclusion (Rodés, 1922). Thus, the controversy over the time difference of SCs began to present a situation in which an endless discussion would continue between Bauer and other scientists.

In this way, the problem was not solved despite the heated arguments. It may be worth noting that Chree referred to the standardization of observation instruments and also that Chapman had already begun to construct a theoretical model of magnetic storms through these discussions. About 10 years later, Chapman and his student Vincenzo Consolato Antonio Ferraro (1907-1974) published a series of pa- 
pers (Chapman and Ferraro, 1931a, b, 1932a, b, 1933) in which they showed a new theory on the mechanism of the initial phase of a magnetic storm. In these very famous papers, Chapman and Ferraro introduced a new concept of magnetic cavity in the cosmic space near the Earth and succeeded in explaining why and how an SC occurs at the beginning of a magnetic storm. The magnetic cavity they introduced can be said to be the primitive idea which can be regarded as the origin of the concept of the later magnetosphere. They also pointed out that the sudden sharp increase in the horizontal force of geomagnetism when an SC took place would be a result of the sudden compression of the magnetic cavity by the space plasma arriving from the Sun. Their predictions were verified about 30 years later through direct observations on artificial satellites.

\section{SC investigation committee proposed by Bauer (1924-1930)}

\subsection{Foundation of international scientific societies}

The International Research Council (hereinafter referred to as IRC) was founded in 1919, in the peaceful atmosphere that reigned in the world after the end of World War I in 1918. The countries in the world began cooperating rather than fighting one another, not only in politics or the economy but also in all fields including science and technology.

A number of scientific societies were founded that were affiliated with the IRC. One of them was the International Geodetic and Geophysical Union (hereinafter referred to as IGGU). The IGGU also had several affiliated groups, among which the group studying geomagnetism was the Section of Terrestrial Magnetism and Electricity (hereinafter referred to as STME).

IGGU held its founding meeting in 1919 in Brussels, Belgium. Its first official meeting was held in Rome, Italy, in 1922 , because it was agreed at the founding meeting that IGGU would meet every 3 years.

\subsection{Launch of the SC investigation committee}

The second meeting of IGGU was held in October 1924 in Madrid. At the same time and same place, STME also held its meeting.

After being elected as the secretary and director of the central bureau of the STME, Bauer proposed, at the STME meeting, launching a project to study and solve the problem of simultaneity of SC. According to Bauer's proposal, a committee on SC investigation was created below STME. Its official name was the "Committee on Observatories, Instruments and Scheme of Operations for Observing Accurately Times of Occurrence of Sudden Commencements of Magnetic Storms", and its aim was to make it clear whether SCs occur simultaneously at various locations on Earth or whether they tend to propagate from one place to another with a finite velocity.

A title of "Adoption of a scheme for observing at selected magnetic observatories the times of occurrence of 'sudden commencements' with special instruments admitting of very high precision in the determination of time" can be seen at the ninth item in the agenda of section "B. Observatory Work" under point "I. Terrestrial Magnetism at the STME meeting in Madrid" (IGGU-STME, 1924). In total, four committees, namely the (a) international comparisons of magnetic instruments, (b) magnetic and electric characterization of days, (c) terminology in terrestrial magnetism and electricity and (d) observatories, instruments and scheme of operations for observing accurately times of occurrence of sudden commencements of magnetic storms are listed in the second item, "Committees recommended by the Section", under "the resolutions of International Section of Terrestrial Magnetism and Electricity" at the Madrid meeting, as is reported by Bauer in the journal Terrestrial Magnetism (Bauer, 1924). This committee (d) is exactly the SC investigation committee proposed by Bauer.

\subsection{Tanakadate from Japan is appointed as the reporter of SC investigation committee}

Aikitu Tanakadate (1856-1952) is a Japanese geophysicist and professor emeritus at the Imperial University of Tokyo. He was the only geomagnetist from Asia to attend the STME Madrid meeting.

Tanakadate was born in 1856 in Ninohe, Iwate prefecture, in northern Japan. After majoring physics in the College of Science, University of Tokyo, he graduated in 1882. In the same year, he obtained a position of associate professor at the University of Tokyo. He studied physics under the guidance of William Thomson (later Lord Kelvin; 1824-1907) at the University of Glasgow during his stay in the UK between 1888 and 1890. Tanakadate was then promoted to professor of University of Tokyo after his return from Europe. He invented an electromagnetic declinometer and also the Tanakadate-style magnetometer and performed geomagnetic surveys all over Japan.

Tanakadate published a very long and detailed paper on the geomagnetic surveys he conducted (Tanakadate, 1904). In this paper, not only did Tanakadate report on the result of these geomagnetic surveys but also analyzed and discussed the data using a new altitude compensation method he invented. During his analysis, Tanakadate treated the nondipolar part of main geomagnetic field carefully in order to correctly detect the magnetic anomalies in the Earth's crust. In addition, he also paid full attention when discussing the data, taking into consideration that one cannot entirely exclude the possibility that some kind of vertical electric current might flow in the air, because it was a matter of discussion among the scientists as to whether vertical electric currents exist or not in the Earth's atmosphere. 
Tanakadate's paper was highly appreciated by the scientists in the world for his innovative way of data analysis; this ensured that Tanakadate's name was known widely by European and American scientists. After this, Tanakadate was recognized as one of the fully fledged geomagnetists of the time. For example, Tanakadate became one of the members of the Commission on Terrestrial Magnetism and Atmospheric Electricity of the International Meteorological Committee in 1910. In 1919, Tanakadate was also elected as the first president of STME on Bauer's recommendation. In this way, Tanakadate built up step by step his position in the international scientific society.

Tanakadate's manuscripts, private letters and personal diaries, as well as his many belongings are preserved and open to the public at the Tanakadate Aikitu Memorial Science Museum in Ninohe, his birthplace. We have performed an intensive research to investigate original documents related to Tanakadate. All the documents kept in this museum are well arranged with serial numbers. We will refer to these serial numbers as the Tanakadate documents (hereinafter abbreviated to TD no.) in this paper.

The committee for SC investigation had no chairperson. It had a reporter instead. Tanakadate, recommended by Bauer, was elected the reporter of this committee at the STME Madrid meeting (TD no. 3412). We suppose Bauer might have expected Tanakadate, an Asian scientist, to play the role of reporter from a neutral standpoint, as the SC propagation simultaneous argument between Bauer and Faris and Chree and other scientists showed an atmosphere of controversy between USA and Europe.

According to the minutes of STME meeting of 4 October 1924, the budget of STME was discussed at this meeting (TD no. 3281). Usage of funds of 40000 French francs per year, requested by STME from the IGGU, was approved for the purposes of (a) publications and miscellaneous expenses of the central bureau, (b) international comparisons of instruments, (c) magnetic and electric characterization of days, (d) construction of instruments for special purposes and (e) grants to committee for special investigations, where the terms "special purposes" and "special investigations" referred to in items (d) and (e) mean SC investigations.

After the budget approval, the SC investigation committee then discussed the development of a new type of highresolution magnetometer which was thought to be essential in order to settle the problem. An induction-type magnetometer, under development by Alexander Crichton Mitchell (1864-1952) at the Eskdalemuir Observatory in the United Kingdom, was also considered as one of the candidates.

Next, Tanakadate, reporter of the SC investigation committee, began coordinating the project. He issued, on 21 November 1924, a "Circular Regarding Sudden Commencements Of Magnetic Storms" and requested that major geomagnetists of the world answer the questions in it no later than the end of May 1925 (TD nos. 3263, 3423; Tanakadate, 1926). Copies of this questionnaire were then sent to 10 famous geomagnetists (Sydney Chapman, Charles Chree, Ewoud van Everdingen (1873-1955) in Holland, Jules Jaumotte (1887-1940) in France, Charles Maurain (1871-1967) in France, Louis Agricola Bauer, Alexander Crichton Mitchell, Luigi Palazzo (1861-1933) in Italy, S. J. L. Rodés, Arthur Schuster (1851-1934) in the United Kingdom) and to one director (of the United States Coast and Geodetic Survey - E. Lester Jones) through Bauer (TD no. 1754) and also to other geomagnetists directly by Tanakadate. Questions given in this questionnaire were (verbatim) as follows:

1. "What kind of instrument would you suggest to use for the purpose of investigating sudden commencements of magnetic storms? Ordinary magnetographs, or currents induced in fixed circuits?"

2. "What magnetic elements should be observed? H, D, $\mathrm{V}(\mathrm{Z})$ or $\mathrm{X}, \mathrm{Y}, \mathrm{Z}$ ? All of them, or only some of them; in the latter case which ones?"

3. "Have you any specifications to suggest for the suspended magnet system, size of magnet, degree of damping, etc.?"

4. "What should be the sensibilities of the instruments? State in gammas per $\mathrm{mm}$ in case of magnetographs, or amperes per $\mathrm{mm}$ in case of galvanometer for induced currents."

5. "What should be the time scale of the recorder? State in seconds per mm."

6. "Would you prefer ordinary photograph, or optically concentrated sharp lines which can be magnified later?"

7. "Would you deem it desirable at present to give a definition of 'sudden commencement,' say gamma per second, or rather leave this for later decision?"

8. "What is your approximate estimate of the cost of the instruments, and also of the running expense of carrying out the work per annum?"

9. "If you have already had experience in the use of such an instrument, kindly give information respecting it in sufficient detail, or supply reference to some publication in which it is described."

Replies from seven scientists were sent back to Tanakadate; these replies came from Chapman (TD no. 3407), Rodés (TD no. 3409), Maurain (TD no. 3420), Bauer (TD no. 3416), van Everdingen (TD no. 3410), Johns (TD no. 3411) and Moidray at Lukiapang Observatory in Shanghai (TD nos. 3408, 3414, and 3448).

The result of this questionnaire showed that most scientists preferred ordinary-type magnetometers (i.e., magnetometers with a small magnet hung by a thin fiber) to Mitchell's 
Table 1. Replies from the scientists to Q.1 ("What kind of instrument would you suggest to use for the purpose of investigating sudden commencements of magnetic storms? Ordinary magnetographs, or currents induced in fixed circuits?") are as follows (French translated by the authors).

\begin{tabular}{ll}
\hline Chapman & $\begin{array}{l}\text { Either kind of instrument would, I think, be suitable, but experiment alone can indicate which kind would be } \\
\text { the better. }\end{array}$ \\
\hline Rodés & A magnetograph. \\
\hline Maurain & $\begin{array}{l}\text { Il serait évidemment utile que des appareils à induction fussent utilisés en même temps que des magnétomèters } \\
\text { oridinaires, et que des mesures des courants telluriques soient faites aussi. [It would be obviously useful if an } \\
\text { induction-type magnetometer is used together with the ordinary magnetometers and if the measurements of Earth } \\
\text { currents are also made.] }\end{array}$ \\
\hline Bauer & It is considered inadvisable to design special instruments. \\
\hline Van Everdingen & Ordinary magnetograph. \\
\hline Jones & Ordinary magnetograph, with improvements in optical arrangements and improvements in driving clock. \\
\hline Moidray & L'expérience me manque. [I lack experience.] \\
\hline
\end{tabular}

Table 2. Replies from the scientists to Q.2 ("What magnetic elements should be observed? H, D, V(Z) or X, Y, Z? All of them, or only some of them; in the latter case which ones?") are as follows.

\begin{tabular}{ll}
\hline Chapman & $\begin{array}{l}\text { I think all three magnetic elements should be observed, and probably H, D, V would be simpler, but X, Y, Z would, } \\
\text { I think, be equally suitable for theoretical purpose. }\end{array}$ \\
\hline Rodés & The declination needle, because it is easier to be manipulated. \\
\hline Maurain & - \\
\hline Bauer & H-variometer. \\
\hline Van Everdingen & Two horizontal components, H and D, or X and Y. \\
\hline Jones & $\begin{array}{l}\text { Experience has shown that the H variometer nearly always gives the most clearly defined record of the beginning, } \\
\text { but the records of the other variometers often supply valuable data, so that it is important to have all three in } \\
\text { operation. }\end{array}$ \\
\hline Moidray & \begin{tabular}{l}
$\mathrm{H}$, ou peut-être X. [H or maybe X.] \\
\hline
\end{tabular}
\end{tabular}

induction-type magnetometer which did not seem to have undergone sufficient experimental verification.

As to the comment inquired about in question nine, many researchers emphasized the importance of improving the time accuracy of observation, uniformity of the rotation of the cylinder in the recorder or sharpness of the light on the recording paper. Besides, Bauer added a comment that a technical term "abrupt commencement" would be more precise than the conventional term sudden commencement.

Bauer expected that Tanakadate would also answer his own questionnaire, but Tanakadate never stated his own view of his questions. It seems that Tanakadate tried to collect the scientists' opinion in a fair way, without any personal bias.

\subsection{Tanakadate's activities as the reporter of SC investigation committee}

During his official trip to Europe, Tanakadate submitted a report on the result of questionnaire, dated 25 August 1925, to the central bureau of STME from his hotel in Paris (TD nos. 3429 and 3445). In this report, Tanakadate indicated that most of the scientists (a) preferred ordinary-type magnetometers to induction-type magnetometers, (b) considered that a sensibility of several nanotesla per millimeter would be sufficient, namely that an extremely high sensitivity of less than $1 \mathrm{nT} \mathrm{mm}{ }^{-1}$ would not be necessary, and (c) agreed that the uniformity and precision of the rotation speed of the recording cylinder would be very important. It is also described in this report that some scientists suggested the need to improve the optical system, and one scientist referred to the terminology by questioning which of the terms, i.e., abrupt or sudden, would be more appropriate.

Tanakadate sent a copy of this report with his letter to Chree dated 26 August (TD no. 3437). This was a reply to Chree's letter to Tanakadate on 22 August. Chree, having received it on 28 August, immediately replied to Tanakadate, who was staying in Paris (TD nos. 3438 and 3439). Tanakadate also responded immediately to Chree (TD no. 3437- 
Table 3. Replies from the scientists to Q.3 ("Have you any specifications to suggest for the suspended magnet system, size of magnet, degree of damping, etc.?") are as follows.

\begin{tabular}{ll}
\hline Chapman & No. \\
\hline Rodés & - \\
\hline Maurain & - \\
\hline Bauer & Variometer, kept in good adjustment and in ordinary operation. \\
\hline Van Everdingen & No. \\
\hline Jones & - \\
\hline Moidray & $\begin{array}{l}\text { La suspension unifilaire est ici préférable. L'aimant beaucoup plus léger que ceux d'Adie. [The unifilar suspension } \\
\text { is preferable here. The magnet much lighter than those of Adie (Patrick Adie's magnetograph).] }\end{array}$ \\
\hline
\end{tabular}

Table 4. Replies from the scientists to Q.4 ("What should be the sensibilities of the instruments? State in gammas per mm in case of magnetographs, or amperes per $\mathrm{mm}$ in case of galvanometer for induced currents.") are as follows.

\begin{tabular}{ll}
\hline Chapman & I suggest $3 \gamma$ per millimetre. \\
\hline Rodés & One millimeter per minute (of declination angle) as the sensibility of the instrument upon the photographic paper. \\
\hline Maurain & - \\
\hline Bauer & 2 gammas per millimeter. \\
\hline Van Everdingen & $1-5$ gamma per $\mathrm{mm}$. \\
\hline Jones & About $2 \gamma$ per $\mathrm{mm}$ is recommended. \\
\hline Moidray & La sensibilité de $1 \mathrm{~mm}$ pour $1 \gamma$. [The sensibility of $1 \mathrm{~mm}$ for $1 \gamma]$. \\
\hline
\end{tabular}

Note: $\gamma$ is an old unit of magnetic field strength and is equal to nanotesla.

2). A copy of this letter was readily forwarded by Chree to Mitchell. Mitchell also wrote a letter to Tanakadate in Paris, pointing out that most scientists favoring ordinary-type magnetometers misunderstood the problem of accuracy (TD nos. 3441 and 3443). Mitchell emphasized in his letter the importance of high-sensitivity and high time resolution instruments for observation, mentioning his plan to develop a more sensitive magnetometer in Edinburgh at a reasonable price.

Tanakadate requested that Mitchell send a more detailed design scheme and an estimate sheet of his magnetometer because the price of GBP 10 (equivalent to about USD 30, based on the exchange rate at that time) that Mitchell had shown was very reasonable. Bauer was very interested in this news provided by Tanakadate. Bauer might have strongly expected that his hypothesis would be finally verified if magnetometers of the same type could be equipped at a number of observatories all over the world and if really a highly sensitive magnetometer can be built in such a low price as Mitchell says.

On 19 October 1925, Tanakadate visited Chree's house in London during his stay in Europe (Fig. 5). Tanakadate writes that it was a fruitful visit as there was a discussion with Chree on various issues, including SC investigation (TD no. 3426). Tanakadate had a plan to visit Bauer in Washington after visiting Chree in London, as his trip back to Japan was scheduled via the USA. But Tanakadate could not meet Bauer because his schedule was changed and he had to travel via Siberia due to some reason, and his visit to the USA was canceled.

After returning to Japan, Tanakadate expected to receive a detailed design and an estimate of price of magnetometer from Mitchell and Chree. However, he was waiting in vain. Bauer also heard nothing from Chree (TD nos. 3405 and 3401). Tanakadate might have been worried about the deadline, as STME requested that he submit a preliminary report of the committee before 1 July 1926 . For this reason, Tanakadate considered developing another type of magnetometer with high sensitivity and high time resolution also in Japan, independent from Chree and Mitchell. Suminosuke Ono (1886-1944) at the Central Meteorological Observatory of Japan (hereinafter abbreviated to CMOJ) was chosen by Tanakadate as the person in charge of developing a new magnetometer.

Tanakadate was due to leave Japan on 11 April 1926 in order to participate in international conferences in Europe. Tanakadate sent a letter to Bauer from Tokyo (TD no. 3488) the day before his departure to Europe. In this letter he wrote 
Table 5. Replies from the scientists to Q.5 (“What should be the time scale of the recorder? State in seconds per mm.”) are as follows.

\begin{tabular}{ll}
\hline Chapman & I suggest 20-40 seconds per millimetre. \\
\hline Rodés & One millimeter per minute of time. \\
\hline Maurain & - \\
\hline Bauer & $20 \mathrm{~mm}$ of abscissa equaling an hour. \\
\hline Van Everdingen & $15-20 \mathrm{~mm}$ per hour. \\
\hline Jones & - \\
\hline Moidray & On espérera alors obtenir 15 secondes. [We will then expect to obtain 15 seconds.] \\
\hline
\end{tabular}

Table 6. Replies from the scientists to Q.6 ("Would you prefer ordinary photograph, or optically concentrated sharp lines which can be magnified later?") are as follows.

\begin{tabular}{ll}
\hline Chapman & I cannot say. \\
\hline Rodés & Optically concentrated sharp lines. \\
\hline Maurain & - \\
\hline Bauer & - \\
\hline Van Everdingen & Ordinary photograph. \\
\hline Jones & Ordinary photographic. Sensitive paper and accurately focused light required. \\
\hline Moidray & $\begin{array}{l}\text { Un trait bien noir d'un ou deux dixième de millimètre. [A very black line with its width of one or two tenths of a } \\
\text { millimeter.] }\end{array}$ \\
\hline
\end{tabular}

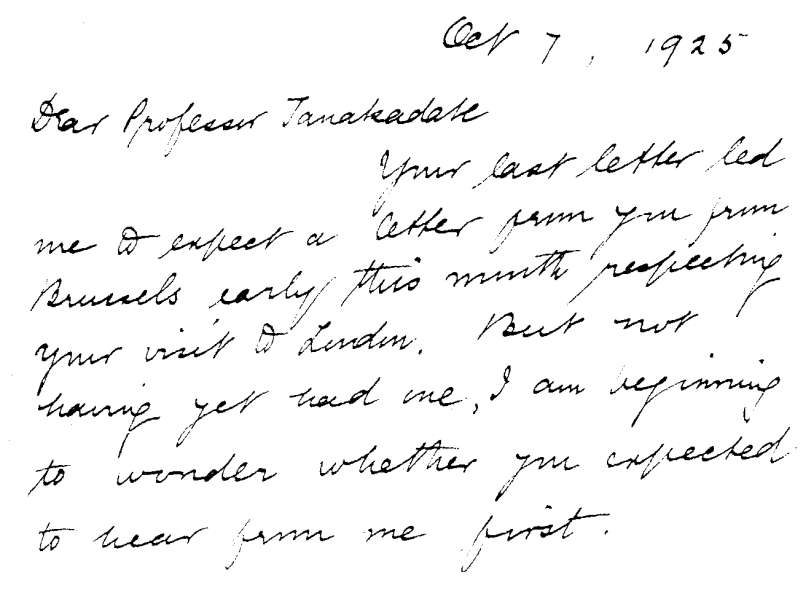

Figure 5. A letter from Chree to Tanakadate, dated 7 October 1925 , concerning Tanakadate's visit to Chree's house in London (TD no. 3435).

to Bauer that "As to the status of the matter relating to Sud. Com. of magnetic disturbance I have nothing to make report upon, as I have had no correspondence with Dr. Mitchell since I left Europe last year ... (omittance) ... I shall meet Dr. Chree and hear what is going on there", and he also wrote "We are trying an instrument of our own making at Kakioka which will have a speed of more than $10 \mathrm{~cm}$ per hour and a sensibility of about 1 gamma/mm".

In fact, Mitchell had already sent Tanakadate a letter, dated 5 April 1926, with a sketch of magnetometer and an estimate of its price of GBP 16.10 per each pair of magnetometers to observe two components of geomagnetic field (TD no. 4758). Tanakadate missed Mitchell's letter by a hair because it arrived just after his departure from Tokyo for Europe.

The two projects for developing a new type of magnetometers by Mitchell and Chree and by Tanakadate and Ono made Bauer very pleased (TD no. 4740). Bauer expected that those magnetometers should play an important role in investigating the mystery of beginning time of sudden commencements of magnetic storms.

But the members of STME were obliged to face a difficulty that neither Bauer, Tanakadate, Chree nor Mitchell had ever anticipated. STME lost a considerable amount of money due to abrupt and steep descent of the exchange rate in French francs (TD nos. 4740 and 4744), as the whole budget of STME was deposited in French francs according to the rules of IGGU. The influence of this economic problem cannot be totally disregarded as being the cause of the slowing down of the promotion of the SC investigation project.

On 1 June 1926, Tanakadate visited Chree again in London to discuss several topics, including the matter of magnetometer developed by Mitchell (TD no. 4742). Mitchell, being in- 
Table 7. Replies from the scientists to Q.7 ("Would you deem it desirable at present to give a definition of 'sudden commencement,' say gamma per second, or rather leave this for later decision?") are as follows.

\begin{tabular}{ll}
\hline Chapman & I would leave this for later decision. \\
\hline Rodés & It is not an easy matter. \\
\hline Maurain & - \\
\hline Bauer & The time has not yet come to make it desirable to give an exact definition of "sudden commencement". \\
\hline Van Everdingen & Later decision. \\
\hline Jones & No. \\
\hline Moidray & $\begin{array}{l}\text { Si on définit bien le mot soudain, on ne semble pas se préoccuper du mot starting, qu'on suppose clair de lui-même. } \\
\text { [If we define the term sudden commencement, we do not seem to be worried about the word starting, which we } \\
\text { assume to be self-explanatory.] }\end{array}$ \\
\hline
\end{tabular}

Table 8. Replies from the scientists to Q.8 ("What is your approximate estimate of the cost of the instruments, and also of the running expense of carrying out the work per annum?") are as follows.

\begin{tabular}{ll}
\hline Chapman & I cannot say. \\
\hline Rodés & All considered some 500 dollars. \\
\hline Maurain & - \\
\hline Bauer & The initial cost would approximate 1000 to 1200 Dollars (or about 15000 francs at the present rate of exchange). \\
\hline Van Everdingen & $\begin{array}{l}\text { It is rather difficult to estimate the cost of the instrument; the cost of photographic paper will be about f162 (25 dol- } \\
\text { lar) per annum. }\end{array}$ \\
\hline Jones & - \\
\hline Moidray & $\begin{array}{l}\text { Je n'ai aucune idée du prix. Il est nécessaire de le fixer le plus bas possible. [I have no idea of the price. It is } \\
\text { necessary to make it as low as possible.] }\end{array}$ \\
\hline
\end{tabular}

formed by Chree that Mitchell's last letter to Tanakadate arrived after his departure from Tokyo, again sent Tanakadate, who was staying in London by then, a letter with the same content as that of the previous letter (TD nos. 3053, 4743 and 4744). Tanakadate, in his reply, suggested that Mitchell should submit a proposal to STME so that his project to develop a new type magnetometer would be accepted as one of the official projects of STME and could secure sufficient funds for the development of magnetometer (TD no. 4744).

On 18 June 1926, a preliminary report of the SC investigation committee, drafted by Tanakadate, was sent to Bauer in Washington from Tanakadate, who was staying in Paris (TD nos. 4745 and 4747). In this preliminary report, Tanakadate reported to Bauer that (a) a new type magnetometer was being developed by Mitchell; (b) according to Maurain, rapidly running recording instruments were tested at the University of Paris, and they might be applicable to magnetometers; (c) the Department of Terrestrial Magnetism of the Carnegie Institution of Washington and the United States Coast and Geodetic Survey were conducting cooperative experiments to increase the time resolution of recording devices; and (d) another type of magnetometer, other than Mitchell's, was also under construction in Japan.

A letter of gratitude for the submission of preliminary report was sent from Bauer to Tanakadate on 11 August 1926 (TD no. 4746). In this letter, Bauer writes the following to Tanakadate:

Regarding the question as to whether Dr. Mitchell is actually proceeding with the construction of his proposed instrument, there is no information on file in my office. Furthermore, in a letter dated 29 July 1926, just received, Dr. Chree stated that he impressed on Dr. Mitchell that no expense of any instrument could be justified without the express authorization of the Administrative Bureau (President, Vice President and Secretary). You will doubtless recall that the allocation of funds to individual investigators is to be made by the Administration Bureau. Accordingly, unless I receive either from you or from Dr. Mitchell a specific request or recommendation, to be submitted to the Administrative Bureau for consideration, the construction of the Mitchell instrument may have to be held in 
abeyance. I may say that, while I am in favor of proceeding, I do not see how the Administrative Bureau can act before the receipt of a special request for funds, especially in view of the depletion of the available funds on account of the reduced value of the French franc.

In this reply, he suspected the feasibility of Mitchell's magnetometer and also implicitly reproved Tanakadate for his imprudent allusion to the budget implementation in his letter to Mitchell.

As stated in Sect. 4.2, STME had several special committees on various scientific topics such as international comparisons of instruments, magnetic and electric characterization of days and terminology in terrestrial magnetism and electricity, in addition to sudden commencement of magnetic storms. STME bulletin no. 6, published in November 1926, was a compilation of reports from those committees. Tanakadate's short report on the SC investigation committee was also included. Indeed, 2 years had already passed since the Madrid meeting, but the SC investigation committee could not show any substantial achievements, except implementation of a questionnaire and submission of preliminary report providing information on the development of two types of new magnetometers by Mitchell in Edinburgh and by Ono in Tokyo, respectively.

\subsection{Studies of SC by other scientists}

In 1925, Bauer published, in the journal Terrestrial Magnetism and Atmospheric Electricity, a long paper concerning SC (Bauer and Peters, 1925). This paper began with an overall review of relevant papers, examined again the data of the past, added and analyzed a new data set and reiterated that the SCs could propagate. Bauer stated in this paper that the time difference of SC between two observational locations should be still finite, although it might be much smaller than those predicted in his previous papers. The new propagation velocity of SC, proposed anew by Bauer, was $1000 \mathrm{~km} \mathrm{~s}^{-1}$, namely about 6 times faster than old values that Bauer used to think of. In addition, Bauer also pointed out that SCs could propagate not only in an east-west direction but also from the Equator to the poles, with a velocity of about 100 to $200 \mathrm{~km} \mathrm{~s}^{-1}$. This is the first paper referring to the possibility of latitudinal propagation of SCs.

Chree promptly wrote a counterargument paper against Bauer (Chree, 1926). This is also a long paper, with detailed discussions on various features of SC. Its assertion, however, can be summarized in that Bauer himself also finally admitted that there did not exist a time difference such that several minutes were required for SCs to go around the Earth, as Bauer had insisted, as the new velocity that Bauer proposed was as fast as $1000 \mathrm{~km} \mathrm{~s}^{-1}$, which took only $40 \mathrm{~s}$ to travel around the Earth. Chree also expected that this problem be solved under the guidance of the SC investigation commit- tee, an official committee established by STME at the Madrid meeting. Chree thought, as he wrote in his paper, that a series of the same type of magnetometers should be equipped at worldwide observatories in order to investigate whether a time difference of less than 1 min exists or not.

Mitchell published, in 1925, a short paper reporting the result of observation of the vertical component of geomagnetic field using an induction-type magnetometer at Eskdalemuir Observatory in Edinburgh from 1919 (Mitchell, 1925). This magnetometer was different from the new type of highly sensitive magnetometer referred to in the previous section which used a permanent magnet, whereas this induction-type magnetometer used a large four-turn coil with a square of $140000 \mathrm{~m}^{2}$ placed in the horizontal plane. The electric current induced by the change of vertical geomagnetic field was measured by a galvanometer connected to the coil. Its sensitivity was $0.0164 \mathrm{nT} \mathrm{s}^{-1} \mathrm{~cm}^{-1}$, with the recording speed of $1 \mathrm{~cm} \mathrm{~min}^{-1}$. According to Mitchell, good quality data were recorded on 4 September 1924. He proclaimed that he had succeeded in determining the SC onset time with an accuracy of $0.1 \mathrm{~min}$ in time using this induction-type magnetometer.

Continuous observations by this induction-type magnetometer at Eskdalemuir Observatory began in January 1926. Henry William Lyon Absalom (1894-1965) tried to compare data from Eskdalemuir Observatory and from Potsdam Observatory (Absalom, 1927). However, Absalom did not show any definitive conclusions on the simultaneity of SCs. He simply stated that induction-type magnetometers could be quite useful for the observation of SCs.

At around the same time, Maurain at the University of Paris also began a similar experiment of measuring electric currents induced in a fixed coil by the change in geomagnetic field. Use of induction magnetometers, which was not very appreciated by the scientists when Tanakadate conducted the questionnaire, now came into consideration.

\subsection{Bauer's illness and death of Chree}

In 1926, an international conference named the Third PanPacific Science Congress was held in Tokyo. Bauer could not attend this conference for several reasons, although Tanakadate wished to see Bauer in Japan to discuss the SC problem (TD no. 4746). Nicholas Hunter Heck (1882-1953) of the United States Coast and Geodetic Survey came to Japan instead. Heck visited Kakioka Magnetic Observatory during his stay, and after returning to the United States, reported to Bauer on the state of progress of the development of Onostyle magnetometer (TD no. 4753). From this, we can know that Ono's new type of highly sensitive magnetometer was built at Kakioka Magnetic Observatory in order to avoid interference from artificial noise sources in Tokyo Metropolis.

In March 1927, Bauer sent a reply to Tanakadate (TD no. 4754). In this letter, Bauer wrote his wish that Ono-style magnetometer would be completed as early as possible. 
The third general assembly of IGGU, and also the meeting of STME, were to be held in Prague, Czech Republic, in this year 1927 (3 years after the Madrid meeting in 1924). In June 1927, Tanakadate departed Japan for Europe via Siberia to attend these meetings.

Tanakadate sent letters to Chree and to Maurain on 10 July and to Mitchell on 11 July, respectively, from Geneva to ask them to report on the progress of development of their magnetometers (TD nos. 4751, 4759 and 4761).

On the same day, 10 July, Tanakadate also sent a letter to Bauer informing him that he would be in Zurich after Geneva, where he would await a reply from Bauer (TD no. 4762).

Chree, Mitchell and Maurain readily replied to Tanakadate staying in Zurich. Mitchell had built two sets of magnetometers which were already used for experimental observations at Eskdalemuir Observatory (TD nos. 4760, 3396 and 3386). Chree provided information that, according to an IGGU officer, the funds allocated to the STME at the previous Madrid meeting would remain available even after the next Prague meeting in case it was not used before that time (TD no. 4757). Chree and Mitchell were preparing to make a report on their magnetometer at the next Prague meeting to ask other scientists their opinions in order to modify and improve it if necessary. They intended to construct several more sets using the remaining amount of the funding. Maurain's induction magnetometer, on the other hand, was still not yet tested, though the instrument itself had already been manufactured (TD no. 4763).

However, a reply from Bauer did not seem to arrive at Tanakadate. Not only this reply but not even one letter from Bauer is not preserved in the Tanakadate documents after this. Bauer is supposed to have fallen into "mental breakdown" (or probably, what is called depression nowadays), presumably around this time.

The general assembly of the IGGU was held in Prague from 3 to 10 September 1927. Chree and Mitchell reported on their newly developed highly sensitive magnetometer. Tanakadate also reported on Ono's magnetometer at the STME meeting (TD no. 3394).

STME met nine times during this period. In total, 30 resolutions were adopted, including the "authorization of the executive committee to take necessary steps to complete the investigation into the times of commencement of magnetic storms", from which we can know that the SC investigation committee continued also after the Prague meeting (Bauer, 1927). But this report, published in Terrestrial Magnetism and Atmospheric Electricity, became the last writing that Bauer presented in public journals; Bauer's disease was becoming worse. Bauer's assistant, John Adam Fleming (1877-1956) of the Carnegie Institution, undertook the editing and issuing of the journal Terrestrial Magnetism and Atmospheric Electricity instead of Bauer.
Not only Bauer but also Chree became ill in the following year. His illness was serious, and he passed away on $12 \mathrm{Au}-$ gust 1928, in England, at the age of 68 (Chapman 1928).

In 1929, Suminosuke Ono, who was working with development of the Ono-style new type of highly sensitive magnetometer at the Kakioka Magnetic Observatory, moved from CMOJ to the Tokyo University of Literature and Science. Thus, the Ono-style magnetometer was used for SC observation at the Kakioka Magnetic Observatory only for a short time. This magnetometer was used later for the geomagnetic observations during the Second International Polar Year, as will be stated in Sect. 5.5.

\subsection{Death of Bauer}

On 1 January 1930, Bauer was awarded the title of the honorary director of the Department of Terrestrial Magnetism of the Carnegie Institution of Washington and retired at the same time from the Carnegie Institution for health reasons (Fleming, 1930a). However, 2 years later, on 11 April 1932, a tragedy took place. Bauer plunged from the second floor of his house and tragically lost his life the next day (TD no. 5328; Nippoldt, 1932).

It is now generally accepted that his death was suicide caused by his illness, that is to say depression, although some people suspected in the past that it was an accident. The reason why Bauer became depressed is not clear. The only thing we can infer is that Bauer fell sick in the summer of 1927, as his very frequent letters to Tanakadate stopped suddenly in July of that year. Bauer was elected to be the president of STME at the Prague meeting in September 1927 (he had been the secretary general of STME for 8 years before that and used to be one of the most active members of STME), but it was impossible for him to continue working due to his illness. Some studies suggest a possibility that Bauer's disease was caused by a drastic change of his working environment at the Carnegie Institution (Hashimoto, 1997), though this hypothesis is of course not definitive. If so, Bauer might have felt more and more isolated in the institution, resulting in his unexpected death in tragedy on 12 April 1932.

After both Bauer, who insisted propagation of SC, and Chree, who insisted simultaneity of SC quitted the stage, the only actor remaining on the stage was Tanakadate. Tanakadate set his mind to solve this problem by himself, bearing Bauer's and Chree's will.

\section{Studies of SC during and after the Second International Polar Year (1930-1945)}

\subsection{Second International Polar Year}

An international scientific project, called the First International Polar Year (abbreviated to IPY I), was carried out from 1882-1883. At the end of this project, it was agreed that the international society would repeat such international cooper- 
ative observations every 50 years, for the purpose of developing the science.

Johannes Georgi (1888-1972) at the Hamburg Ocean Meteorological Observatory is considered as being the first to have noticed this agreement 50 years before. He noticed this and proposed to fulfill it at a meteorological meeting in November 1927. For this reason, the Second International Polar Year (abbreviated to IPY II) was mainly planned on the initiative of the International Meteorological Committee (abbreviated to IMC). The actual plan was written out by the Commission for Réseau Mondial and Polar Meteorology, which was established by the IMC.

In 1929, IMC decided to launch a special committee for the execution of IPY II. For this purpose, the International Commission for the Polar Year was organized in IMC. Danish scientist Dan Barfod la Cour (1876-1942) was elected its chairperson. This commission met in August 1930 in Leningrad (present St. Petersburg) in Russia to determine in detail the period, target, method of observation, etc. (Anonymous, 1930).

Some of the scientists suggested postponing IPY II by several years because the solar cycle would be minimum 50 years after IPY I when the solar cycle had been at its maximum. In addition, there were dissenting opinions against the execution of IPY II for financial reasons, as the world had already entered an unprecedented large economic crisis which began on "Black Thursday" (24 October 1929). It was agreed, however, as the result of various discussions, to perform IPY II from 1 August 1932 to 31 August 1933, as had been promised 50 years before.

\subsection{IUGG Stockholm assembly}

IGGU held its fourth general assembly in Stockholm from 14 to 23 August 1930. A new name, the International Union of Geodesy and Geophysics (abbreviated to IUGG) was formally adopted from this meeting in place of IGGU, according to the resolution voted at the last meeting in Prague. STME also began using a new name, i.e., International Association of Terrestrial Magnetism and Electricity (abbreviated to IATME), after this meeting.

In response to the proposal from IMC to organize a special committee for the polar year, the IUGG launched the Polar Year Commission. The chairperson of this commission was Fredrik Carl Mülertz Størmer (1874-1957) from Norway.

Tanakadate intended to settle the SC problem during the IPY II under the leadership of the SC investigation committee. Hence, Tanakadate endeavored to set up a project in STME/IATME to observe SCs more intensively under international cooperation (TD no. 3465). However, no resolution concerning SC observation was adopted at the Stockholm STME meeting, as shown in the report published in Terrestrial Magnetism and Atmospheric Electricity (IGGU-STME, 1930). It is simply written that "studies of sudden commencements of geomagnetic storms were discussed" during the "reports and discussions on special subjects in pursuance of the resolutions adopted at the Prague meeting", but no new project was adopted to investigate SCs, and nothing was referred to on the SC investigation committee. In the same way, no description about SC observation can be seen in the report of the STME/IATME Stockholm meeting written by Fleming, although other subjects such as magnetic characterization of the days, terminology and international comparison of the instruments are still presented in his report (Fleming, 1930b).

In contrary to Tanakadate's efforts, scientists seem to have already lost their enthusiasm for SC investigation after Bauer's illness in 1927 and Chree's death in 1928. They might have felt that this enigmatic problem came to a deadlock because even a clue was not found to solve it, although 20 years had passed since the problem was questioned by Bauer in 1910. The times were exactly when epoch-making new fields appeared and succeeded in general physics, such as the special theory of relativity in 1905 , the general theory of relativity in 1916 or quantum mechanics in 1925. Watching such a situation in the neighborhood, geomagnetic researchers might have been frustrated and impatient.

After that, European and American geomagnetic researchers focused mainly on magnetic disturbances in highlatitude regions such as polar magnetic storms (called substorms now). Studies of the geomagnetic phenomena in high latitudes became the major interests of the scientists, while the long-existing problems, such as SC were regarded as already obsolete subjects to study. Neither Mitchell nor Maurain published papers on SC after that. It is unknown how their magnetometer went later. Since Mitchell was also the chairperson of the committee for investigation of the magnetic characteristics of the days, he might not have been able to concentrate solely on SC research. As for the magnetometer of Mitchell, there is a description that its development was interrupted due to lack of budget (TD no. 2836).

Thus, the STME/IATME Stockholm meeting closed without any new resolutions on SC investigation. The SC investigation committee became merely a titular committee with no substantial activity. As the SC investigation committee went into dissolution in practice, Tanakadate decided to investigate SC personally, outside the official activities of STME/IATME.

\subsection{Magnetometer network proposed by la Cour}

Dan Barfod la Cour, a Danish scientist and also the chairperson of the International Commission for the Polar Year of IMC, invented a more sensitive magnetometer using quartz as the fiber for suspending a magnet. This magnetometer, named QHM (Quartz Horizontal Magnetometer), was combined with a rapidly rotating cylinder for high time resolution recording. La Cour had a plan to set up a network of QHM's in order to observe rapid variations in the geomagnetic field worldwide (Stauning, 2000). 
The IMC had a commission on geomagnetism, namely the Commission of Terrestrial Magnetism and Atmospheric Electricity (abbreviated as CTMAE). This means that there were two geomagnetic societies, IATME in IUGG and CTMAE in IMC, standing in parallel. Both do not seem to have cooperated very much with each other, although they did not confront each other as rivals. Members of CTMAE met when the general assembly of IMC was held at Innsbruck, Austria, in September 1931, to determine the detailed observation plan during IPY II. The words "net of observatories", "net of stations" and "high-speed magnetic registration" can be seen in its report (Harradon, 1931a, b). These are supposed to be related to la Cour's QHM network project.

Tanakadate was fortunate in that la Cour's QHM network was constructed and equipped around the world, as he would later conduct $\mathrm{SC}$ research using the rapid-run magnetograms sent from the observatories where la Cour's QHM were deployed, because this magnetometer was a very strong instrument for SC observation, although it was not exclusively targeted at SC observation but was aimed at a broader research purpose.

Tanakadate was active enough in CTMAE and in IATME. For example, he submitted a paper titled "Sudden commencement of magnetic disturbances (Dr. Aikitu Tanakadate)" to a meeting of the Sectional Committee on Meteorology and Terrestrial Magnetism held on 31 May 1932 (TD no. 3026).

\subsection{SC observation at the Central Meteorological Observatory of Japan (CMOJ)}

Since European and American scientists were loosing their interest in SC, Tanakadate intended to continue in Japan.

In Japan, a subcommittee, named International Polar Year Subcommittee, was created in 1931 below the Science Research Council to promote scientific observations in Japan during IPY II, with Tanakadate as its chairperson. Tanakadate proposed adding $\mathrm{SC}$ research to the observation plan.

During the period of IPY II, CMOJ and Tokyo University of Literature and Science respectively carried out SC observations on Japanese territory.

SC observations made by CMOJ will be described first. This observation was planned by Shuiti Imamiti (18941989), director of the Kakioka Magnetic Observatory of CMOJ. Imamiti himself wrote his reminiscences of this observation (included in One Hundred Years of Geophysical Observation; (Nagata and Fukushima, 1983; published by the University of Tokyo Press). He writes the following (Imamiti, 1983; translated from Japanese by the authors):

At that time, I thought of observing sudden commencements of magnetic storms at our three stations Toyohara, Tsingtao and Kakioka during the Second International Polar Year. This idea came from my recollection that Professor Aikitu Tanaka- date would have been in charge of chairing an international committee for investigating sudden commencement of magnetic storms. I made up an overview of observation plan, without consulting Professor Tanakadate, and submitted it to our director, Dr. Takematsu Okada of CMOJ. This plan was therefore executed by CMOJ, with the approval of Dr. Takematsu Okada.

The three stations described in Imamiti's essay were Toyohara (now Yuzhno-Sakhalinsk) on Sakhalin Island, Russia, Tsingtao (now Qingdao) in China, and Kakioka in Ibaraki prefecture, Japan.

The Southern half of Sakhalin Island was Japanese territory from the Russo-Japanese War until the end of the World War II. The Toyohara Provisional Magnetic Observatory was built there by CMOJ, especially for the sake of IPY II. This observatory was taken over by the former Soviet Union after World War II and continues its observation even now as the Yuzhno-Sakhalinsk Geomagnetic Observatory of Russia.

Tsingtao, now spelled Qingdao, in Shandong province, China, used to be the German concession in China. It was then occupied by Japan after the Japan-Germany battle in Tsingtao during World War I. In 1915, Tsingtao Meteorological Observatory, where the Germans also made geomagnetic observations, was requisitioned by Japan and managed by the Japanese Navy. After its transfer from the Japanese Navy to CMOJ in 1923, geomagnetic continuous observations were resumed at this observatory.

Highly sensitive Eschenhagen-type single fiber $H$ component magnetometers used for these observations were manufactured at the factory of CMOJ. They were combined with automatic self-recorders invented by Imamiti and improved by the CMOJ in order to increase its time resolution up to $12-15 \mathrm{~mm} \mathrm{~min}^{-1}$. In total, three sets of the same type equipment were built and used at Kakioka (observer Shūiti Imamiti), Toyohara (observer - Hisanao Hatakeyama) and Tsingtao (observer - Kosaburo Ito) observatories.

There were three distinct SCs that occurred on 14 October 1932, 30 April 1933 and 29 May 1933 (dates given are based on universal time, UT), respectively, among which the SC on 30 April was the largest. Imamiti concluded, from the analysis of these SCs, that SCs propagated with a longitudinal speed of $800 \mathrm{~km} \mathrm{~s}^{-1}$ from west to east and a latitudinal speed of 100 to $200 \mathrm{~km} \mathrm{~s}^{-1}$ from the Equator to the poles (Imamiti, 1938).

Imamiti also pointed out complexity of waveform of SCs in this paper, classifying SCs into group I (SCs whose horizontal intensity increases after a small decrease prior to it; corresponding to $\mathrm{SC}^{*}$ at present) and group II (normal SC whose horizontal intensity increases monotonically after its onset). He wrote the following (translated from Japanese by the authors):

It was not easy to read exactly at which moment an SC began, since its trajectory arose very gradu- 
ally on the rapid-run magnetogram. Onset times of group I SCs were relatively easy to read compared to those of group II SCs. Moreover, it may not be obvious, for an SC belonging to group I, whether defining the onset time by the minimum point in its horizontal intensity was appropriate or not.

The time of the minimum horizontal force, in case of a group I SC, tends to delay with increasing latitude. Both delays of $10.4 \mathrm{~s}$ between ToyoharaKakioka and $12.9 \mathrm{~s}$ between Toyohara-Tsingtao would far exceed the reading error.

In addition to SCs, Imamiti also analyzed the simultaneity of the onset time of geomagnetic pulsations using the data from these three stations. He concluded that geomagnetic pulsations would be simultaneous, in contrast to SCs, with a time difference of less than $1 \mathrm{~s}$ between any pair from these three stations.

Imamiti's results were communicated to Tanakadate through Takematsu Okada (1874-1956), director of the Central Meteorological Bureau of Japan. Tanakadate, on receiving Imamiti's report, sent a joint circular with Maurain, the secretary general of IATME, to geomagnetic observatories all over the world, to request geomagnetic data of the same three SCs as Imamiti observed (TD no. 2915). Geomagnetic data from 29 observatories were sent to Maurain in Paris before September 1933 and were then transferred to Tanakadate in Tokyo. The final number of observatories providing data amounted to 40 , owing to the magnetometer network constructed by la Cour.

\subsection{Observation by Ono at Tokyo University of Literature and Science}

Another observation of SC during IPY II was made at Shimoda, Izu Peninsula, Japan, by Suminosuke Ono of the Tokyo University of Literature and Science (Tokyo Bunrika Daigaku; present University of Tsukuba). He moved from CMOJ to this university, as stated at the end of Sect. 4.6.

This observation was planned by Tanakadate, and was executed by Ono under the supervision of Tanakadate, while the SC observation by Imamiti stated in the previous section was planned independently of Tanakadate.

Ono observed SCs during IPY II at the Marine Laboratory of the Tokyo University of Literature and Science. A magnetometer of the hydrographic department type was used for absolute observations, and an Ono-style magnetometer was used for variation measurements (Fig. 6). This observation began in August 1932, in Shimoda, where the Marine Laboratory was located.

During this observation, Ono also captured the same SCs as the ones Imamiti observed. According to his paper, Ono (1934a) did not compare them with data sent from other stations due to lack of time, and hence, he did not judge whether the SCs are simultaneous or not. He cited instead

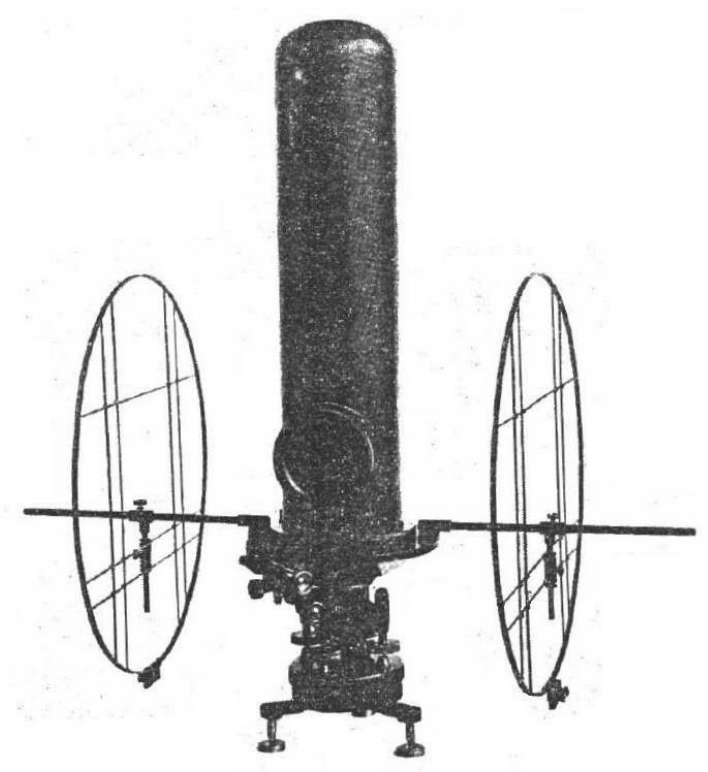

Figure 6. Ono-style magnetometer (after Ono; Geophysical Magazine, Tokyo, 3, 1930).

Tanakadate's conclusion on SC simultaneity; this will be discussed in the next section. Besides, Ono proclaimed in this paper that he had confirmed relationship between geomagnetic changes and Earth currents and the existence of periodic variation of some kind with its period of about $1 \mathrm{~d}$ (different from geomagnetic diurnal variation on solar quiet days) accompanying magnetic storms.

\subsection{Tanakadate's report at Lisbon meeting}

Tanakadate, examining again the overall data of Imamiti, Ono and worldwide stations sent through Maurain, obtained a conclusion that SCs would be almost simultaneous within the accuracy of observational error at various places on Earth. This result was reported by Tanakadate (1934) at the IATME meeting which met during the IUGG Lisbon general assembly from 17 to 24 September 1933 .

A draft of his Lisbon report can be found in Tanakadate documents (TD no. 2836). Viewing the draft, we know that Tanakadate derived two conclusions before presenting this report.

One conclusion is on the simultaneity of SC. Tanakadate judged, from rapid-run magnetograms of 29 stations, that the time differences of an SC onset were within the range of several seconds all over the world, which can be thought not to exceed the observational errors of the instruments used.

The other conclusion he arrived at is the complexity of waveform when an SC occurs. It had been thought that an $\mathrm{SC}$ would begin instantaneously, as its name implies. How- 
ever, rapid-run magnetograms revealed that the definition for the exact onset time of SCs should be examined as a new problem because the onset point of an SC was not always self-evident on a rapid-run magnetogram. Imamiti's definition of the onset for an SC, in the case of group I, was the minimum point of the initial slight decrease in the horizontal force before its increase. Tanakadate noted in this draft that la Cour suggested an alternative definition, namely a definition that the starting point of such a small decrease rather than its minimum might be more suitable. Thus, rapid-run magnetographs contributed to a more detailed observation of $\mathrm{SC}$ by recording the expanded waveforms that had not been recorded on the normal-run magnetographs before.

Tanakadate's conclusion on SC study is also presented in Ono's (1934b) paper published in the next year. The following is taken from it (translated from Japanese by the authors):

As for SCs of magnetic storms, a large SC appeared on 1 May, Japan Standard Time (30 April UT) this year, and two fairly large SCs, respectively, on 15 October (14 October UT) last year and on 29 May this year. All these SCs were well observed at Kakioka (observer - Imamiti), Toyohara (observer - Hatakeyama) and Shimoda (observers - Ono and Imazato) stations. A report on the observation of these SCs was submitted to the IATME meeting held in Lisbon in September this year. Since Professor Tanakadate was also the reporter of the SC investigation committee of IATME, he made a lot of effort to collect data from all over the world; he analyzed them together with domestic data and reported them at the IATME Lisbon meeting. The onset times deduced from these data seem to be almost simultaneous across the world. Data of some stations show a time difference of more than one minute, but those stations adopt a low-speed recording system, for example, one rotation per day. Therefore, errors in reading the onset times at such stations are thought to be considerably large. Meanwhile, stations equipped with rapid-run magnetographs reported almost coincident onset times, with an accuracy of less than one minute. A time difference of less than one minute can well be considered as being within the observational errors. The magnetogram shows very gradual changes, if the trace is magnified on the registration paper, and thus, the onset time read from the trace by an observer would vary, largely depending on the observer's definition of onset of magnetic storms. This means that a time difference, even if it exists, must be comparable to or less than the observational errors. Dr. la Cour, the chairperson of the International Commission for the Polar Year, appreciated these results of the Second International Polar Year, referring to the improvements in recording the waveform of $\mathrm{SC}$ with high time resolution of one tenth of a minute.

A similar discussion can be seen in a review paper written by Hisanao Hatakeyama (1905-1994) 5 years after the IPY II (Hatakeyama, 1938). Hatakeyama writes the following (translated from Japanese by the authors):

Many magnetic storms begin suddenly. Whether this beginning time is simultaneous all over the world or whether it propagates from one place to another is an important matter in order to examine the mechanism of magnetic storms. This is exactly the reason why the problem of simultaneity of SCs had been studied for a long time. In Japan, Imamiti of the Kakioka Magnetic Observatory designed a highly sensitive rapid-run magnetograph for the purpose of observing SCs at Kakioka, Toyohara and Tsingtao stations during the Second International Polar Year (1932-1933). The recorded data showed that SCs could be regarded as being simultaneous within the accuracy of a few seconds. Angenheister's study was often referred to with regard to the simultaneity of SCs, but our observation succeeded in acquiring much more accurate data than ever discussed. This was our great success.

As stated in Sect. 5.4, Hatakeyama was the director of the Toyohara Provisional Magnetic Observatory and was also the observer at Toyohara of the three SCs that Imamiti discussed. Hatakeyama concluded that SCs would be simultaneous, while Imamiti proclaimed that SCs would propagate, although they used the identical data set. The same data were also adopted in Tanakadate's report; both Kakioka and Toyohara observatories were included in the 29 stations that Tanakadate analyzed to deduce the simultaneity of SCs (TD no. 2836).

Imamiti took the minimum point in geomagnetic horizontal force as the definition of the onset time of group I SC he named, namely $\mathrm{SC}^{*}$ (as it is called today). This might have led him to misunderstand that SCs would propagate in the latitudinal direction because the DP (dominant in polar regions) field, producing a small minimum before sudden increase in the horizontal force, would be larger with increasing latitude, resulting in an apparent delay of the minimum point. Hatakeyama's definition, on the other hand, is not known as he did not mention it explicitly. We can only infer that Hatakeyama might have considered la Cour's suggestion for the definition of SC onset when he concluded the simultaneity of SC.

\subsection{SC studies after the Second International Polar Year until the end of World War II}

A report on the sudden commencements of magnetic storms by Tanakadate can be seen below the heading "III. Reports 
and discussions in pursuance on resolutions passed in the Stockholm Assembly" in the provisional minutes published in Terrestrial Magnetism and Atmospheric Electricity, volume 38 (IUGG-IATME, 1933). In this session, Tanakadate presented a preliminary report on the result of his analysis of SC, using data of Imamiti, Ono and worldwide stations sent through Maurain (Tanakadate, 1934).

At this IATME Lisbon meeting, Rodés at the Ebro Observatory in Spain proposed a research project on SC. A resolution stating "Diurnal variation of sudden commencement of magnetic storms - Father Rodés having been attracted to the interest of this study, the question is referred to the Executive Committee" is listed as the 14th of the 23 resolutions adopted at the Lisbon meeting (Fleming and Harradon, 1933). Besides, Alvin Greene McNish (1903-1993) from the USA also reported on his research results about SC (McNish, 1934a, b).

After this IATME meeting, Johannes Egedal (1891-1965) in Denmark wrote a paper in which he criticized Tanakadate's method of analyzing SC as presented in Lisbon (Egedal, 1934). He proclaimed that it would not be possible to determine whether SCs are simultaneous or not by using Tanakadate's data set, insisting that the time required for an $\mathrm{SC}$ to propagate over a distance equal to the Earth's radius would not exceed $1 \mathrm{~min}$ if hypothesizes that SCs are triggered by arrival of charged particles from the Sun that migrate from dusk to dawn direction near the Earth.

The next IUGG meeting after Lisbon took place in Edinburgh in 1936 (Fleming and Harradon, 1936). There was almost no progress on SC investigation in the 3 years from Lisbon to Edinburgh. In the minutes of the Edinburgh meeting, a "Report of Commission on the study of sudden commencements of magnetic storms (author's note: the word commission should be committee; this may be a simple misprint)" is shown in section "VIII. Reports of Commissions and Reporters appointed at the Lisbon Assembly" (IUGG-IATME, 1936). This tells us that the SC investigation committee still existed at the time of the Edinburgh meeting. Tanakadate submitted a paper on SC, but this paper was simply a review of Imamiti's result that SCs would propagate while geomagnetic pulsations would be simultaneous. This report was not read by Tanakadate himself as he did not participate in this assembly. He was already 80 years old in this year and was too old to travel from Japan to Europe.

In addition, Japan's withdrawal from the League of Nations due to the Manchurian Incident also prevented Japanese nationals from traveling abroad. According to One hundred years of surveying and mapping, published by the Geographic Survey Institute of Japan (the present Geospatial Information Authority of Japan; Geographic Survey Institute of Japan, 1970, p. 551), Chūji Tsuboi (1902-1982) and several delegates were sent to the United Kingdom to attend the IUGG general assembly, and Hisashi Noto (1897-1980), who was a researcher of thunder and lightning and was studying in the United Kingdom, attended the IATME meet- ing (IUGG-IATME, 1937). However, it is unclear at present whether Noto read Tanakadate's report on SC in Edinburgh or whether it was read by someone else.

No work on SC was done in Japan after the Edinburgh IATME meeting, except a study of SC conducted by Hantarō Nagaoka (1865-1950). Nagaoka was a famous theoretical physicist in Japan, professor emeritus of the University of Tokyo and one of the old colleagues of Tanakadate at University of Tokyo. He built an induction-type magnetometer to observe rapid changes in geomagnetism. An experimental observation was carried out from 1936 at the Kakioka Magnetic Observatory, using his induction-type magnetometer. Nagaoka analyzed an example of SC observed by this magnetometer and proposed his own idea that $\mathrm{SC}$ would take place when a flux of electric field lines emitted from the Sun hit the Earth's ionosphere (Nagaoka, 1941).

The next IUGG general assembly was held in Washington, D.C., from 4 to 15 September 1939 (Fleming et al., 1939). The assembly opened just $4 \mathrm{~d}$ after Germany's invasion of Poland (the outbreak of World War II). The USA government was very nervous about international political relations. IUGG was even notified by the USA government that the content of the conference should be limited to purely scientific discussions. Although participants from Germany and also from other European countries canceled their journey to the USA, the assembly became the largest one ever because the number of participants from South American countries increased largely, offsetting the decrease in the number of participants from Europe.

From Japan, only three persons Motonori Matuyama (1884-1958), Chūji Tsuboi and Kōji Hidaka (1903-1984) were allowed to join this IUGG Washington general assembly (Geographic Survey Institute of Japan, 1970, p. 551) because Japan's international position was becoming more difficult with the progress of World War II. At the IATME meeting of this IUGG general assembly, periodic surveys of geomagnetism carried out by CMOJ and by the Hydrographic Department of Japan were reported as research activities in Japan during this period, while nothing was referred to in relation to investigation on SC any more (Fleming et al., 1939).

Most of the existing committees continued after this IATME Washington meeting, and it is written in its minutes that " 9 of 10 committees were reappointed and in some cases additional members were added". However, there is no description about which committee was not reappointed, and consequently, we do not know whether the committee discontinued was the SC investigation committee or not.

Japan entered the Pacific War in 1941. After that, an extreme priority was given to military research, and purely scientific research was postponed until after the end of the war. Of course there is no information at present on the SC investigation committee in the aftermath. 


\section{Discussions}

\subsection{Advantage of automatic recording system and discovery of SC}

In discussing the discovery of SC, we can notice that the invention of self-recording instruments by Brooke and by Ronalds mentioned in Sect. 3.1 was a milestone event for the development of science in three ways.

First, a continuous recording became available which was not possible when only eye observations were made; that is, the data were expressed as a line instead of a set of points. This continuous data set brought about much larger significance to the observation than the discrete data set obtained by previous intermittent eye observations. This greatly increased the amount of information. The actual observation curve replaced the not necessarily objective curve guessed from interpolation between the dots.

Second, it contributed a lot to improving the quality of observation. The style of observation shifted from ocular readings of the values in constant attendance to periodic replacement of photographic paper at scheduled times and periodic confirmation of working status of the instrument, which has significantly reduced the workload of observers. In the age of eye observations, human errors in reading the values could not be completely excluded. For example, a wrong reading of the scale or an error in time of reading the value could have occurred due to fatigue or carelessness of the observer, especially in case of nighttime observations. The invention of automatic registration system solved these problems.

Third, it provided scientists with much more objective data. Anyone can read the value on photographic paper after the invention of self-recording, while only one observer could read the value when the eye observation method was used. After the invention of an automatic, continuous recording system, many people can first discuss, by looking at the curve on the registration paper, and then determine the reading, or multiple readings by different persons can be statistically processed to reduce personal errors. In this sense, the invention of self-recording instruments contributed to the progress of science by improving the objectivity of the data.

These merits of an automatic and continuous recording system would have contributed to the discovery of SC. Qualitative features of suddenly beginning magnetic storms were probably already known in the period of eye observation, but quantitative discussion became possible only after the introduction of automatically recording magnetometers. It was not revealed until its invention what the amplitude of increase in the horizontal geomagnetic force was or how quickly this sudden increase occurred over time (rise time). Those values were first read on the photographic paper of the magnetogram. As a result, most of the magnetic storms were found to begin within a few minutes (which was almost comparable to the temporal resolution of a normal-run magnetograph), as it showed an almost stepwise trajectory on the photographic recording paper.

Brooke and Airy did not show any example of a magnetogram that seemed to record an SC in their paper. They only wrote the following in the caption of a figure: "Plate VII (Fig. 9). The commencement of the magnetic storm of 5 September 1896. The oil lamp was in use, and this shows its inability to impress the photographic paper during rapid movements of the magnet, when the registration is most important" (Brooke, 1847a, b). This sentence clearly describes that the magnet moved very quickly at the beginning of a magnetic storm, suggesting that Brooke and Airy had already noticed the existence of a sudden commencement of a magnetic storm. If they had used a smaller light source and/or an additional lens to improve the width of trajectory, they could perhaps have proved their advantage in the discovery of SC. Therefore, at this stage, judging who was the first discoverer of SC still does not seem to be definitive, although a strong hypothesis can be set up that Brooke and Airy might be one of the most likely candidates.

\subsection{On the earliest discoverer of the simultaneity of SC}

The discovery of SC was discussed in the previous section. In this section, we will discuss on the first discoverer of the simultaneity of SC.

A typical magnetic storm begins with an almost stepwise enhancement of the horizontal geomagnetic field. A question was raised as to whether or not the timing of this stepwise change could be regarded as almost simultaneous all over the world.

We proposed in this paper that Capello in Portugal could be nominated as its first discoverer, as highlighted in Sect. 3.3. Capello had already found this phenomenon in 1863 and had published it in 1864, 16 years earlier than Adams and Ellis, in 1880, did. However, Capello's discovery did not attract the attention of the scientists, and it has been forgotten in history. It seems to us that there exist two reasons for this.

One reason is the lack of reference to Capello's paper in the papers of Adams and Ellis. For this reason, later scientists were only able to trace back to their papers, without being able to access Capello's paper. It is unclear why they did not cite Capello's paper. It may probably be due to a simple fact that neither Adams nor Ellis noticed Capello's work 16 years before. When Adams and Ellis published their papers in 1880, neither Capello nor his co-author Stewart proclaimed their priority, or they might not even have noticed the papers by Adams and Ellis.

Another reason that we suspect is its relationship to James Clerk Maxwell's prediction of electromagnetic waves. The electromagnetic wave was predicted by Maxwell in 1864, that is, in the same year as Capello's discovery was published. Therefore, Capello had no idea that his discovery 
might have some relationship to the predicted electromagnetic waves when he published his article.

Furthermore, most of the scientists were rather doubtful about the existence of electromagnetic waves when Maxwell published his prediction. It was not easy for the scientists at that time to accept the new concept of a displacement current introduced by Maxwell. People thought it could only be accepted after an electromagnetic wave was really confirmed through actual experiments. However, the existence of the electromagnetic wave was not readily reported. As for its discovery, that would have to wait for more than 20 years before Hertz performed a ring coil experiment in 1887. For this reason, the validity of Maxwell's equations, and hence the electromagnetic wave as their consequence, were still in doubt in the 1860s. Hence, neither Capello himself nor his co-author Stewart nor other scientists were conscious of the possibility that the simultaneity of SC might be related to Maxwell's electromagnetic wave, leaving society unconcerned with Capello's discovery.

As several previously known formulas were later found to be derivable from Maxwell's equations owing to advancement in theoretical studies, scientists began admitting the validity of Maxwell's equations in the 1870s. In this decade, because the essential nature of light was strongly suspected to be a kind of electromagnetic wave, the existence of electromagnetic waves was considered almost certain, and the scientists became interested in the phenomena occurring almost simultaneously on Earth in connection with the search for electromagnetic waves which propagate at the speed of light. Since Adams and Ellis reported the simultaneity of SC at this time, their papers caught the attention of the society for this reason.

Unfortunately, neither Adams nor Ellis cited Capello's paper. Capello's discovery was forgotten. If prior works are not cited appropriately in later papers, those papers will easily be lost in the bibliography, and their achievements and/or discoveries will be forgotten in history forever.

\subsection{Stubbornness of Bauer}

Guglielmo Marconi (1874-1937) was working with long distance communication using radio waves. His experiment of transatlantic communication between Europe and North America in 1901 and 1902 led Arthur Edwin Kennelly (1861-1939) and Oliver Heaviside (1850-1925) to predict the existence of an electrically conductive layer above the ground (now called ionosphere) that could reflect radio waves.

In 1910, Bauer, in the USA, presented a propagation hypothesis of SC. According to Bauer's hypothesis, an SC occurs and propagates with a limited speed much slower than the speed of light. His hypothesis came from an idea that some kind of triggering event such as a volcanic eruption might produce a sound wave in the atmosphere. This atmospheric vibration might induce some electric currents in the electrically conductive layer if it exists and could make a magnetic storm to ignite, Bauer proclaimed.

Very few scientists supported Bauer's opinion, but Bauer never gave up his SC propagation hypothesis and persisted in it until his death in 1932. It was quite uncertain whether SCs were simultaneous or they could propagate when Bauer submitted his hypothesis in 1910 due to insufficient accuracy of magnetometers in that time. However, the possibility that SCs would be simultaneous widened as observations progressed later. Nevertheless, Bauer stubbornly denied it. Bauer firmly believed his opinion that SCs could propagate; he expected that observational instruments with a higher resolution would definitively prove his hypothesis and pursued its time difference as if he were chasing a dream. But the more accurately the observations were made, the smaller the obtained time difference was. Bauer tried to explain it by assuming a larger propagation velocity than before or even by assuming propagations to latitudinal direction in addition to longitudinal direction. In this way, Bauer impelled himself into a dead end.

Bauer stubbornly insisted on the propagation of SC, despite numerous observational results suggesting the simultaneity of SC. It may be easy to criticize him as a thickheaded scientist. However, it may also be possible to assess him as a strong-minded person who pursued his hypothesis throughout his life with unwavering confidence and passion, if we look at him from another point of view. How many scientists can have the good fortune to pursue their own hypothesis throughout their life while most scientists tend to prefer moving on to current themes or themes resonating with the opinion of the vast majority? There might have been scientists who seemed to be against Bauer, but in fact they simply chose their attitude only by looking at the situation from the perspective of which simultaneity hypothesis and propagation hypothesis would be supported by the majority.

We should examine here why the issue was not solved despite these intensive and long-standing discussions. This is, of course, because the mechanism of SC was much more complicated beyond the expectations by the scientists at that time. Neither the concept of the solar wind nor the magnetosphere existed when they discussed this problem, not to mention the DP field in high latitudes or DL (dominant in low latitudes) field in low latitudes or PRI (preliminary reverse impulse) or geomagnetic pulsations superimposed onto the waveform of SC (see, e.g., Araki, 1994). It would not be very hard for us to imagine now how difficult it was for the scientists at that time to try to understand the mechanism of SC.

\subsection{Tanakadate's neutral attitude as a reporter}

After Bauer in the USA presented a propagation hypothesis of SC in 1910, Chree in the United Kingdom and also other scientists in Europe immediately proclaimed the simultaneity of SC, which went against Bauer's opinion. Argu- 
ments between them escalated, and they criticized each other. Overly heated arguments began to present an atmosphere of some sort of nonscientific, probably more or less emotional, competition between the USA and Europe. Of course neither Bauer nor Chree wanted to discuss this problem be from an unscientific point of view.

Tanakadate from Japan was appointed as the reporter of the SC investigation committee in 1924. This was probably in order to avoid, as much as possible, emotional discussions between Europe and North America by appointing a neutral person from Asia. This is exactly the same as why Bauer requested each observatory to determine the onset time of SCs from a neutral standpoint rather than determining it by each researcher.

Since Tanakadate readily perceived the reason for his appointment, he carefully tried to maintain a neutral stance in dealing with the SC problem and also in chairing the SC investigation committee. For example, Tanakadate never answered his own questionnaire concerning SC observations, even after being requested to do so by Bauer.

Most of the scientists receiving a copy of this questionnaire replied to Tanakadate. However, replies from Chree and Mitchell did not arrive - even after the deadline. It seems to us that there had been some kind of personal and emotional discord between Bauer and Chree and Mitchell. In his letter to Tanakadate, Chree writes, as if annoyed, about "Dr. Bauer's old view that SCs take 3 to 7 minutes to go round the Earth" (TD no. 3439), while Bauer also writes to Tanakadate, "You will be interested to know that I am just in reception of a letter from Dr. Chree, in which he claims that he had not received a copy of your Questionnaires. My assistant, who is very careful in such matters, not only sent him a copy, but also one to Dr. Crichton Mitchell.... (omission) ... I can see no valid excuse why Drs. Chree and Mitchell did not sent [sic] replies to your Questionnaire..." (TD no. 3421). But, in another letter to Tanakadate, Chree writes, "I have a faint recollection of writing something, probably to Dr. Bauer, on the suitability of the questions in your questionnaire. But, so far as I remember, I have had no opportunity of expressing my personal views on the questions. Also what exactly the questions finally propounded were, I cannot deduce with certainty from your summary of answers" (TD no. 3439). Mitchell also writes to Tanakadate, "For various reasons I did not reply to your circular letter on the subject of determining more accurately the times of sudden commencements of magnetic storms" (TD no. 3441). Chree and Mitchell might have regarded Tanakadate as favoring Bauer, although Tanakadate himself tried to listen fairly to all researchers. This is probably because Bauer commended Tanakadate as the first president of STME in 1919 (Bauer, 1919) and also because Tanakadate once wrote a joint paper with Bauer (Tanakadate and Bauer, 1908). Thus, it was never easy to eliminate all emotional problems among the scientists, despite Tanakadate's efforts to keep a neutral standpoint (Fig. 7).

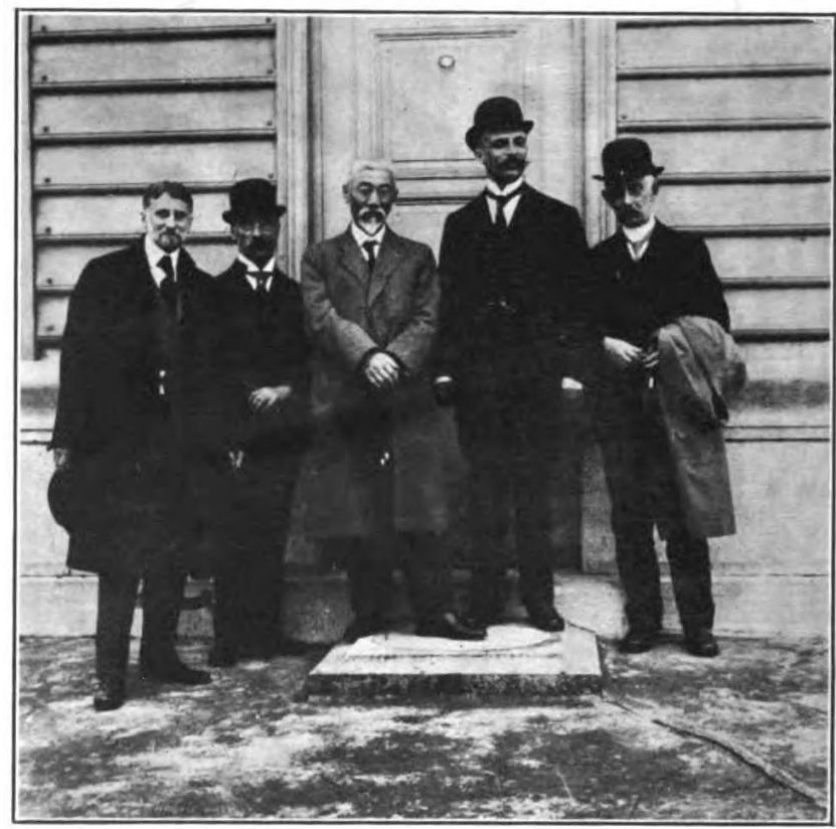

Figure 7. Chree (far left), Tanakadate (center) and Bauer (far right) at Uccle Observatory in 1919 (from Terrestrial Magnetism and Atmospheric Electricity, 24, p. 104, 1919).

Tanakadate also engaged actively in the development of new magnetometers with higher sensitivity and resolution. $\mathrm{He}$ aimed to solve the problem by making more precise observations. He made a maximum effort to promote the development of new magnetometers because he believed that objective data would finally settle the problem.

For this reason, Tanakadate did not express any personal view concerning the simultaneity or propagation of SC for nearly a decade after his appointment as the reporter of SC investigation committee in 1924 and obstinately persisted in a neutral standpoint as its reporter. While this may be regarded as having been correct in some respects, it seems, on the other hand, that Tanakadate, only by persisting in collecting objective data, improving observation methods or developing more highly sensitive instruments, failed to derive any effective conclusions although he had been in charge of the reporter of the committee for more than a decade. He was in principle an experimental physicist, and surely he was quite diligent in collecting objective data by observations or experiments, but he does not necessarily seem to have been very positive in applying these data to theoretical studies such as introduction of new equations or the construction of new physical models. Theories on the initial phase of magnetic storms were proposed by Chapman and Ferraro in 1931 (Chapman and Ferraro, 1931a, b, 1932a, b, 1933), independently from the SC investigation committee. It seems regrettable that no contribution was made by the SC investigation committee to the theoretical studies. 


\subsection{Standardization and development of magnetometers}

The SC investigation committee led by Tanakadate was not able enough to contribute to the theoretical studies of SC as noted above, but the committee surely contributed to the development and standardization of magnetometers.

For example, the SC investigation committee played a certain role in setting up a global observation network that had several chains of observatories equipped with the same type of magnetometers. This requirement to equip a number of stations with the same type of magnetometers accelerated the development of manufacturing magnetometers at a lower cost.

The need to observe SCs and geomagnetic pulsations helped observatories to introduce rapid-run magnetographs, since SCs and geomagnetic pulsations were phenomena with very short timescales. For this purpose, highly sensitive magnetometers were designed and built by Mitchell and Ono, respectively. In addition, induction-type magnetometers were also tested by Mitchell and Maurain in order to observe short period geomagnetic variations.

In this way, the fact that magnetometers with higher specifications have been developed in connection with SC investigations should be properly evaluated and recognized.

\subsection{Trial of SC observations at Kyoto}

The United Kingdom, Germany and Sweden planned to send expedition teams to Antarctica from 1902 to 1903. An international cooperative observation named the "International terrestrial-magnetic cooperation during the period of South Polar research in the years 1902-1903" was launched and executed from 1 February 1902 to 15 February 1903 for the purpose of making meteorological and geomagnetic observations simultaneously with these expeditions to Antarctica (Anonymous, 1901).

The first and 15th days of each month were named "term days", which were special days for intensive observations. Specific time lasting for $1 \mathrm{~h}$ on the term day, that is, the "term hour", was designated as being the most important observation time during which each geomagnetic observatory was requested to record all three components of geomagnetic field with a high paper speed of $24 \mathrm{~cm} \mathrm{~h}^{-1}$, if possible (Farr, 1902).

These intensive observations were aimed to capture "rapid variations in geomagnetic field", which was one of the hot topics discussed among scientists in that time. The term of rapid variations in geomagnetic field mentioned here would mean sudden commencements or geomagnetic pulsations at present. It should be noted here that sudden commencement was already included in the observation targets before Bauer's proposal to observe SCs in 1910.

Tanakadate was also organizing preparations to carry out this "International terrestrial-magnetic cooperation during the period of South Polar research in the years 1902-1903" in Japan. For this purpose, a provisional geomagnetic observatory was built at Kamigamo, Kyoto, and a Mascarttype magnetometer used in Nagoya was moved from Nagoya to Kamigamo because Kyoto was less noisy than Nagoya. Shinzo Shinjo (1873-1938), associate professor at the Kyoto Imperial University, was in charge of this observation.

Tanakadate and Shinjo thought that rapid-run observation would be essential to capture these rapid variations in the geomagnetic field. Since the photographic paper used for rapidrun observation was very expensive, Tanakadate and Shinjo initially made rapid-run observation only twice a month, each observation lasting $1 \mathrm{~h}$, in accordance with the term hours. However, they failed to record rapid variations in geomagnetic field. This led them to a guess that the probability was too small for such a variation to occur just during the term hours, which were only $2 \mathrm{~h}$ in a month. So they had no choice but to perform rapid-run observation all day long, every day. Nevertheless, rapid variations in geomagnetic field were still not captured.

After several trials, Tanakadate and Shinjo finally came to the conclusion that the time constant of a Mascart-type magnetometer was too long to observe rapid variations in geomagnetic field. Therefore, this observation at Kyoto was aborted in 1909.

We should note here that this observation at Kyoto was carried out earlier than Tanakadate's appointment as the reporter of SC investigation committee in 1924. This means that Tanakadate spontaneously made this SC observation in Japan before his participation in an international network of SC study. This pioneering SC observation in Kyoto by Tanakadate and Shinjo can be said as the origin of SC observations in Japan, although they did not succeed in recording actual SCs.

\subsection{Observation of geomagnetic rapid variations at Aburatsubo}

Failing to record rapid variations in geomagnetic field at Kyoto, Tanakadate realized the limit of Mascart-type magnetometer. Due to this failure, Tanakadate ordered Sumio Kadooka (years of birth and death unknown), a lecturer at the Imperial University of Tokyo, to develop a more sensitive rapid-run magnetometer with a shorter time constant. Kadooka's magnetometer was completed in 1910 and was installed at Aburatsubo at the tip of the Miura Peninsula. An experimental observation started in this year.

The magnetometer developed by Kadooka had a sensitivity of $0.15 \mathrm{nT} \mathrm{mm}^{-1}$, and its time resolution was approximately $20.2 \mathrm{~cm} \mathrm{~h}^{-1}$. This magnetometer was sufficiently capable of clearly capturing and recording rapid variations in geomagnetic field. At first, Kadooka himself was in charge of this observation, but once he moved to the Imperial Army in 1911, Torahiko Terada (1878-1935), an associate profes- 
sor at the Imperial University of Tokyo, succeeded him. This observation lasted until 1914.

Terada analyzed the data obtained from this observation and published a long paper concerning the daily variation in geomagnetic pulsations (Terada, 1917). In this paper, Terada discussed in detail the characteristics of daily variation and polarity of the observed geomagnetic pulsations. He attempted to explain those characteristics theoretically, by introducing a daily variation of quasi-static electric current which flows in a highly conductive layer (which was thought to exist almost certainly at that time; later it was termed the ionosphere), also taking into account electromagnetic inductions arising in the Earth's crust.

Thus, Terada discussed in great detail the geomagnetic pulsations recorded by Kadooka's magnetometer. Nevertheless, Terada made no reference to any SCs in his paper. But, in fact, not only geomagnetic pulsations but also SCs were recorded by Kadooka's magnetometer. Looking at an article written by Ono (1937), we will find the following paragraph (translated from Japanese by the authors):

Twenty years ago, the experimental observation planned by Dr. Tanakadate, and actually carried out by Prof. Terada at Aburatsubo, Miura Peninsula, revealed that the onset of an SC was never a sudden, i.e., stepwise, change but was a gradually rising phenomenon - if we expand its waveform enough.

This sentence written by Ono clearly shows that SCs and geomagnetic pulsations were recorded by Kadooka's magnetometer. Although Terada did not refer to SC in his paper, he seems to have had some idea on SC, as can be seen in the following diary entry on 7 January 1921 (Terada, 1921; translated from Japanese by the authors):

I advised Kunitomi (note by the authors: a young scientist at the CMOJ; 1892-1964) to investigate the relationship between suddenly beginning magnetic storms and the location of sunspots.

\subsection{Significance of Tanakadate's research in Japan}

After the death of Bauer and Chree, Tanakadate intended to settle this problem by himself. He planned more detailed observations in the Japanese territory during the Second International Polar Year (1932-1933).

During this period, Shuichi Imamiti at CMOJ also developed his own plan to observe SCs. He was the first person in Japan to plan SC observations independently from Tanakadate because Shinjo in the Meiji era, Kadooka and Terada in the Taishō era and Ono in the Shōwa era studied SC under the supervision of Tanakadate. Okada and Hatakeyama assisted Imamiti in his observations.

After the Second International Polar Year, Nagaoka observed SCs by an induction-type magnetometer of his own design placed at the Kakioka Magnetic Observatory (Nagaoka, 1941).

In this way, very many Japanese scientists worked on SC problem since before World War II. Their work constructed a traditional basis of SC investigation in Japan. This tradition can be seen in the fact that many Japanese geomagnetic researchers also studied SCs after World War II and contributed to the development of geomagnetism. In this sense, studying the history of SC investigation before the end of World War II seems to be important for understanding the whole history of geomagnetism as well.

\section{Conclusions}

The early history of SC investigation is discussed in this paper, with particular emphasis on its history before World War II. For this purpose, we have investigated a number of old materials such as century-old books stored in the dusty and musty basements of libraries. We also often referred to the precious collections of Tanakadate Aikitu Memorial Science Museum, Ninohe, Japan. Deciphering the history by researching large numbers of old references in the libraries was really akin to restoring a dinosaur by collecting fossil fragments buried in a vast desert.

The first conclusion we showed in this paper is of the earliest discoverer of the simultaneity of SC at different two places on Earth. We found that Capello, in Portugal, had already discovered the simultaneity of SC in both Lisbon and London and published it in 1864, 16 years earlier than Adams and Ellis reported the similar phenomenon in 1880 . We also pointed out that the term sudden commencement was probably be first used by van Bemmelen in 1906.

The second conclusion of this paper is how Aikitu Tanakadate acted as the reporter of SC investigation committee within the framework of an international organization (STME/IATME). Tanakadate's activities as the reporter of SC investigation committee of STME/IATME were not fully known. We traced his activities by investigating the materials preserved in Tanakadate Aikitu Memorial Science Museum, including the letters exchanged between him and other scientists, such as Bauer or Chree. He sent copies of a questionnaire to many scientists regarding the observation method of SC and reported its results at STME/IATME meetings. Tanakadate also provided information for STME/IATME regarding highly sensitive magnetometers that were under construction by Mitchell in Edinburgh and Ono in Tokyo, respectively.

The third conclusion is concerned with Tanakadate's research activities on SC after the deaths of Bauer and Chree. Tanakadate tried to continue SC studies in Japan during the period of the Second International Polar Year 1932-1933. At the Central Meteorological Observatory of Japan, more SC research was executed at three stations in the Japanese territory of the time by Imamiti and others, independently from 
Tanakadate. Tanakadate analyzed the data of the magnetic network using rapid-run magnetometers invented by la Cour and the data of Imamiti and Ono and concluded that SCs would occur almost simultaneously on the Earth. Tanakadate also suggested that more detailed studies would be necessary to understand SC because SC shows a very complex waveform according to the location of observation. These activities formed a traditional basis of SC investigation in Japan, prompting a number of Japanese scientists to study SC after World War II.
Geomagnetism has become an integrated and comprehensive science called "Earth and planetary science". Scientists are now studying phenomena not only of the Earth but also of the each planet in the solar system. But in such an epoch, it would be meaningful and useful to trace the works of our predecessors - what they questioned 100 years ago, what they thought and how they struggled and challenged to solve this enigmatic problem by, as the famous old Chinese saying goes, "visiting the old while finding the new". 


\section{Appendix A}

Locations appearing in this paper are shown in the map (Fig. A1).

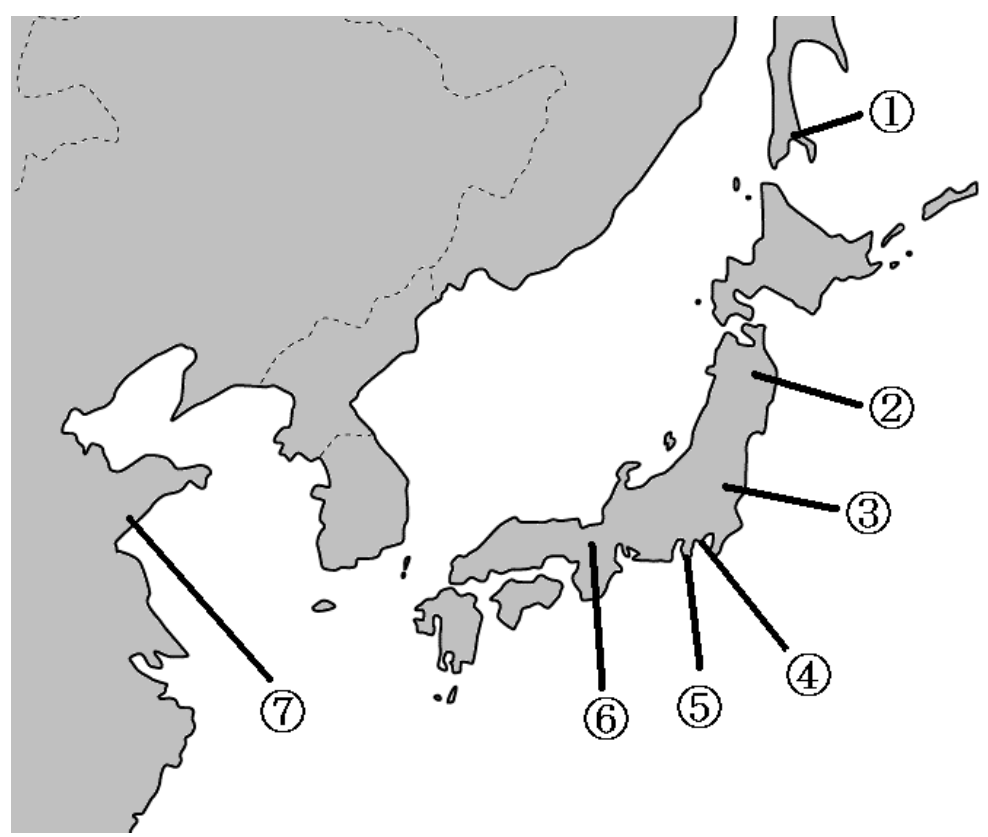

Figure A1. A map showing the locations of places in this paper. (1) Toyohara (now Yuzhno-Sakhalinsk), (2) Ninohe, (3) Kakioka, (4) Aburatsubo, (5) Shimoda, (6) Kyoto and (7) Tsingtao (now Qingdao). 


\section{Appendix B}

Major events described in this paper are listed in the timeline (Table B1).

Table B1. Timeline.

\begin{tabular}{|c|c|}
\hline Year & Event \\
\hline 1600 & Gilbert - "De Magnete" \\
\hline 1634 & Gellibrand - discovery of geomagnetic secular variation \\
\hline 1722 & Graham - discovery of geomagnetic diurnal variation \\
\hline around 1800 & Humboldt - "magnetic storm" \\
\hline 1839 & Gauss - "General Theory of Terrestrial Magnetism" \\
\hline 1846 & Brooke and Airy - invention of automatic recording system, and probable discovery of SC \\
\hline 1864 & Capello and Stewart - discovery of simultaneity of SC \\
\hline 1902 & Tanakadate and Shinjo - trial observation of rapid geomagnetic variations at Kyoto \\
\hline 1906 & Van Bemmelen - "sudden commencement" \\
\hline 1910 & Bauer - propagation hypothesis of SC; Tanakadate and Terada - observation at Aburatsubo \\
\hline 1911 & Chree and others - criticism against Bauer's SC propagation hypothesis \\
\hline 1919 & Foundation of IRC, IGGU and STME \\
\hline 1924 & SC investigation committee in STME; Tanakadate - questionnaire on SC investigation. \\
\hline 1925 & $\begin{array}{l}\text { Tanakadate - Report on the result of the questionnaire; Mitchell - begins to develop a new type } \\
\text { of highly sensitive magnetometer }\end{array}$ \\
\hline 1926 & $\begin{array}{l}\text { Ono - begins to develop a new type of highly sensitive magnetometer; Tanakadate - provisional } \\
\text { report of the SC investigation committee }\end{array}$ \\
\hline 1927 & Bauer - fell ill (mental breakdown); Ono - Ono-style magnetometer almost complete \\
\hline 1928 & Chree - passed away \\
\hline 1931 & Chapman and Ferraro - theory of the initial phase of magnetic storms \\
\hline 1932 & $\begin{array}{l}\text { Bauer - Passed away; the Second International Polar Year; Imamiti and others - observation of } \\
\text { SC at Kakioka, Toyohara and Tsingtao; Ono and Tanakadate - Observation of SC at Shimoda }\end{array}$ \\
\hline 1933 & Tanakadate - analysis of SC using data of la Cour's QHM magnetometer network \\
\hline 1934 & Tanakadate - Lisbon report \\
\hline 1937 & Tanakadate - Edinburgh report \\
\hline
\end{tabular}


Appendix C: Abbreviations

CMOJ Central Meteorological Observatory of Japan

CTMAE Commission of Terrestrial Magnetism and Atmospheric Electricity

IATME International Association of Terrestrial Magnetism and Electricity

IGGU International Geodetic and Geophysical Union

IMC International Meteorological Committee

IPY International Polar Year (I and II)

IRC International Research Council

IUGG International Union of Geodesy and Geophysics

QHM Quartz Horizontal Magnetometer

SC sudden commencement (of magnetic storm)

STME Section of Terrestrial Magnetism and Electricity

TD Tanakadate document 
Data availability. The sources referred to as Tanakadate documents in this paper are preserved in the Tanakadate Aikitu Memorial Science Museum (Tanakadate Aikitu Kinen Kagakukan) and are open to the public.

Author contributions. Both YS and HN participated in the investigations and analysis of Tanakadate documents and other archives. YS wrote the paper in discussion with HN.

Competing interests. The contact author has declared that neither they nor their co-author has any competing interests.

Disclaimer. Publisher's note: Copernicus Publications remains neutral with regard to jurisdictional claims in published maps and institutional affiliations.

Acknowledgements. The authors wish to thank the editor, Dr. Kristian Schlegel, the topical editor, Dr. Takashi Kikuchi and the three reviewers, for their assistance and valuable suggestions.

Review statement. This paper was edited by Takashi Kikuchi and reviewed by Shigeru Fujita, Tohru Araki, and one anonymous referee.

\section{References}

Absalom, H. W. L.: The times of recent "sudden commencements" of magnetic storms at Eskdalemuir, Terr. Mag., 32, 1-4, 1927.

Adams, W. G.: Comparison of curves of the declination magnetographs at Kew, Stonyhurst, Coimbra, Lisbon, Vienna, and St. Petersburg, Brit. Ass. Rept., 50, 201-209, 1880.

Adams, W. G.: On magnetic disturbances and earth-currrents, Brit. Ass. Rept., 51, 463-474, 1881.

Adams, W. G.: Comparison of simultaneous magnetic disturbances at several observatories, Philos T. R. Soc. Lond., 183, 131-140, 1892.

Airy, G. B.: Results deduced from measurements of terrestrial magnetic force in the horizontal plane, at the Royal Observatory, Greenwich, from 1841 to 1876 , Proc. Roy. Soc. London, 39, 255-258, 1886.

Angenheister, G.: Ueber die Fortpflanzungsgeschwindigkeit magnetischer Störungen und Pulsationen. Bericht über die erdmagnetischen Schnellregistrierungen in Apia (Samoa), Batavia, Cheltenham und Tsingtau im September 1911, Nachrichten der K. Gesell. der wissenshaften zur Göttingen, Math.-Phys. Klasse, 4, 565-581, 1913.

Angenheister, G.: Ueber die Fortpflanzungs-Geschewindigkeit Erdmagnetischer Stoerungen und Pulsationen, Terr. Mag., 25, 2631, 1920.

Anonymous: Programm der internationalen erdmagnetischen Cooperation während der Zeit der Südpolar-Forschung in den Jahren 1902-1903, Terr. Mag., 6, 49-58, 1901.
Anonymous: (But in fact supposed to be written by Fleming, J. A. and Peters, W. J.) Resolutions passed by the Polar Year Commission of the International Meteorological Committee at Leningrad, August 1930, Terr. Mag., 35, 245-248, 1930.

Araki, T.: A Physical Model of the Geomagnetic Sudden Commencement, Geophys. Monogr., 81, 183-200, 1994.

Bauer, L. A.: Notice of magnetic disturbance during eruption of Monte Pelée, Martinique, Terr. Mag., 7, 57-58, 1902.

Bauer, L. A.: Beginning and propagation of magnetic disturbance of May 8, 1902, and of some other magnetic storms, Terr. Mag., 15, 9-20, 1910a.

Bauer, L. A.: Analysis of the magnetic disturbance of January 26, 1903, and general considerations regarding magnetic changes, Terr. Mag., 15, 21-30, 1910b.

Bauer, L. A.: The physical theory of the Earth's magnetic and electric phenomena - No. I, Terr. Mag., 15, 107-128, 1910c.

Bauer, L. A.: The physical theory of the Earth's magnetic and electric phenomena - No. II, Terr. Mag., 15, 219-239, 1910d.

Bauer, L. A.: On the simultaneity of abruptly-beginning magnetic storms, Nature, 85, 306-308, 1911a.

Bauer, L. A.: The non-simultaneity and the generally eastward propagation of sudden magnetic storms, Nature, 86, 9-12, 1911b.

Bauer, L. A.: Data for abruptly beginning magnetic disturbances, 1906-1909, No. I, Terr. Mag., 16, 85-108, 1911c.

Bauer, L. A.: Data for abruptly beginning magnetic disturbances, 1906-1909, No. II, Terr. Mag., 16, 163-204, 1911d.

Bauer, L. A.: Terrestrial magnetism and electricity at the Brussels Meetings, 18-28 July 1919, Terr. Mag., 24, 105-112, 1919.

Bauer, L. A.: Terrestrial magnetism and electricity at the Madrid Meeting, October 1924, Terr. Mag., 29, 205-210, 1924.

Bauer, L. A.: Preliminary report on terrestrial magnetism and electricity at the Prague Assembly, 3 to 10 September 1927, Terr. Mag., 32, 169-170, 1927.

Bauer, L. A. and Peters, W. J.: Regarding abruptly-beginning magnetic disturbances, Terr. Mag., 30, 45-68, 1925.

Birkeland, K.: The non-simultaneity and the generally eastward propagation of sudden magnetic storms, Nature, 86, 79, 1911a.

Birkeland, K.: The simultaneity of certain abruptly-beginning magnetic disturbances, Nature, 87, 483-484, 1911b.

Bonifácio, V., Malaquias, I., and Fernandes, J.: Solar photography in the Nineteenth Century: the Case of the Infante D. Luiz Observatory in Lisbon (1871-1880), Journal of Astronomical History and Heritage, 10, 101-113, 2007.

Brooke, C.: On the automatic registration of magnetometers, and other meteorological instruments, by photography, Abs. Paper. Comm. Roy. Soc. London, 5, 657, $1843 \mathrm{a}$.

Brooke, C.: On the automatic registration of magnetometers, and other meteorological instruments, by photography III, Abs. Paper. Comm. Roy. Soc. London, 5, 851-852, 1843 b.

Brooke, C.: On the automatic registration of magnetometers, and other meteorological instruments, by photography, Phil. Trans. Roy. Soc. London, 137, 59-68, 1847a.

Brooke, C.: On the automatic registration of magnetometers, and other meteorological instruments, by photography, Supplement (Supplement communicated by G. B. Airy), Philos. T. R. Soc. Lond., 137, 69-77, 1847b.

Capello, J. C. B. and Stewart, B.: Results of a Comparison of Certain Traces Produced Simultaneously by the Self-Recording Magnetographs at Kew and at Lisbon; Especially of Those 
Which Record the Magnetic Disturbance of July 15, 1863, Proc. Roy. Soc. London, 13, 111-120, 1864.

Chapman, S.: On the times of sudden commencement of magnetic storms, Proc. Phy. Soc. London, 30, 205-214, 1918.

Chapman, S.: Charles Chree, Terr. Mag., 33, 185-187, 1928.

Chapman, S. and Bartels, J.: Geomagnetism, Vol. I and II, Oxford Univ. Press, London, 1049 pp., 1940.

Chapman, S. and Ferraro, V. C. A.: A new theory of magnetic stroms, Terr. Mag., 36, 77-97, 1931a.

Chapman, S. and Ferraro, V. C. A.: A new theory of magnetic stroms, Terr. Mag., 36, 171-186, 1931b.

Chapman, S. and Ferraro, V. C. A.: A new theory of magnetic stroms, Terr. Mag., 37, 147-156, 1932a.

Chapman, S. and Ferraro, V. C. A.: A new theory of magnetic stroms, Terr. Mag., 37, 421-429, 1932b.

Chapman, S. and Ferraro, V. C. A.: A new theory of magnetic stroms, Terr. Mag., 38, 79-96, 1933.

Chree, C.: On the supposed propagation of "equatorial" magnetic disturbances with velocities of the order of 100 miles per second, Proc. Phy. Soc. London, 23, 49-57, 1910.

Chree, C.: The non-simultaneity and the generally eastward propagation of sudden magnetic storms, Nature, 86, 78-79, 1911.

Chree, C.: Time measurements of magnetic disturbances and their interpretation, Proc. Phy. Soc. London, 26, 137-153, 1914.

Chree, C.: The times of 'sudden commencements' (S.C.s) of magnetic storms: observation and theory, Proc. Phys. Soc. London, 38, 35-46, 1926.

Curto, J. J., Araki, T., and Alberca, L. F.: Evolution of the concept of Sudden Storm Commencements and their operative identification, Earth Planet. Space, 59, i-xii, 2007.

Egedal, J.: On the propagation of magnetic storms, Terr. Mag., 39, 321-324, 1934.

Ellis, W.: Correspondence of phenomena in magnetic storms, Nature, 23, 33-34, 1880.

Ellis, W.: On the simultaneity of magnetic variations at different places on occasions of magnetic disturbance, and on the relations between magnetic and earth current phenomena, Proc. Roy. Soc. London, 52, 191-212, 1892.

Faris, R. L.: Times of abruptly beginning magnetic disturbances, as recorded at the coast and geodetic survey magnetic observatories, Terr. Mag., 15, 93-105, 1910.

Faris, R. L.: On the non-simultaneity of suddenly beginning magnetic storms, Nature, 87, 78, 1911a.

Faris, R. L.: On time scaling of magnetograms, Terr. Mag., 16, 109112, $1911 b$.

Farr, C. C.: Proposal regarding high speed magnetic observation on international term days, Terr. Mag., 7, 26-27, 1902.

Fleming, J. A.: Summary of the year's work, department of terrestrial magnetism, Carnegie Institution of Wishington, Terr. Mag., 35, 231-236, 1930a.

Fleming, J. A.: Preliminary report on terrestrial magnetism and electricity at the Stockholm Assembly, 14-23 August 1930, Terr. Mag., 35, 209-212, 1930b.

Fleming, J. A. and Harradon, H. D.: Fifth General assembly of the Association of Terrestrial Magnetism and Electricity at Lisbon, Portugal, 14 to 23 September, Terr. Mag., 38, 313-322, 1933.

Fleming, J. A. and Harradon, H. D.: Sixth General assembly of the Association of Terrestrial Magnetism and Electricity at Ed- inburgh, Scotland, 17-26 September, Terr. Mag., 41, 355-362, 1936.

Fleming, J. A., Harradon, H. D., and Joyce, J. W.: Seventh General assembly of the Association of Terrestrial Magnetism and Electricity at Washington, D.C., 4-15 September 1939, Terr. Mag., 44, 471-480, 1939.

Geographic Survey Institute of Japan (Kokudo Chiri-In): SokuryoChizu Hyakunen-shi (One hundred years of surveying and mapping), 673 pp., 1970.

Glassmeier, K.-H and Tsurutani, B. T.: Carl Friedrich Gauss - General Theory of Terrestrial Magnetism - a revised translation of the German text, Hist. Geo. Space Sci., 5, 11-62, 2014.

Gosling, J. and Pizzo, V.: Formation and Evolution of Corotating Interaction Regions and their Three Dimensional Structure, Space Sci. Rev., 89, 21-52, 1999.

Graham, G.: An Acount of Observations made of the Variation of the Horizontal Needle at London, in the later Part of the Year 1722, and beginning of 1723, Philos. T. R. Soc. Lond., 33, 96107, 1724.

Halley, E.: An Account of cause of the Change of the Variation of the Magnetical Needle, with an Hypothesis of the Structure of the Internal parts of the Earth: as it was proposed to the Royal Society in one of the late Meetings, Philos. T. R. Soc. Lond., 16, 563-578, 1692.

Harradon, H. D.: Abstract of the Innsbruck meeting of the Commission of Terrestrial Magnetism and Atmospheric Electricity of the International Meteorological Organization and of the resolutions adopted 21-23 September 1931, Terr. Mag., 36, 319-323, 1931a.

Harradon, H. D.: Abstract of the Innsbruck meeting of the International Commission for The Polar Year 1932-33 of the International Meteorological Organization and of the resolutions adopted 23-26 September 1931, Terr. Mag., 36, 324-332, 1931 b.

Hashimoto, T.: Rui Baua no Chijiki kenkyu to daiichijisekaitaisen (Louis Bauer's geomagnetic studies and World War I), J. Hist. Sci., Jpn. Ser. II, 36, 1-7, 1997.

Hatakeyama, H.: Wagakuni ni okeru kenkyu wo toshite mita chikyu jikigaku (Geomagnetism reviewed based on the studies in Japan), Weather Serv. Bull., 9, 121-134, 1938.

Imamiti, S.: Jikiarashi oyobi myakudo no hatsugenji hikaku ni kansuru chosa (investigation on the comparison of onset times of magnetic storms and pulsations), Memoirs of Kakioka Magnetic Observatory, 1, 32-43, 1938.

Imamiti, S.: Dai-ni-kai kyokunen kansoku ni tsuite (On the Second Polar Year) in: Chikyu Kansoku Hyakunen(One Hundred Years of Geophysical Observation), edited by: Nagata, T. and Fukushima, N., University of Tokyo Press, 236-242, 1983.

IGGU-STME: International Geodetic and Geophysical Union, Section of Terrestrial Magnetism and Electricity, Agenda for Madrid meeting, 1-10 October 1924 Transactions of the Madrid Meeting, October, 1924, Terr. Mag., 29, 85-86, 1924.

IGGU-STME: International Geodetic and Geophysical Union, Section of Terrestrial Magnetism and Electricity, Provisional agenda for Stockholm meeting, Terr. Mag., 35, 171-173, 1930.

IUGG-IATME: International Union of Geodesy and Geophysics, International Association of Terrestrial Magnetism and Electricity, Lisbon assembly, 17-24 September, Terr. Mag., 38, 241-242, 1933.

IUGG-IATME: International Union of Geodesy and Geophysics, International Association of Terrestrial Magnetism and Electric- 
ity, Meeting in Edinburgh, September 1936, Terr. Mag., 41, 223224, 1936.

IUGG-IATME: International Union of Geodesy and Geophysics, International Association of Terrestrial Magnetism and Electricity, Participation in the meetings, IATME Bull., 10, 7-8, 1937.

Krogness, O.: On the simultaneity of "abruptly-beginning" magnetic storms, Nature, 85, 170-171, 1910.

Malin, S. R. C.: Historical introduction to geomagnetism, in: Geomagnetism Vol. 1, edited by: Jacobs, J. A., Academic Press, London, 1-49, 1987.

Malin, S. R. C. and Barraclough, D. R.: Humboldt and the Earth's magnetic field, Q. J. R. Astr. Soc., 32, 279-293, 1991.

McNish, A. G.: Occurrence of sudden commencements at Waterloo Magnetic Observatory, Comptes Rendus de l'Assemblée de Lisbonne, 1933, IATME Bull., 9, 234-238, 1934a.

McNish, A. G.: Mean force-vectors associated with sudden commencements and magnetic storms, Comptes Rendus de l'Assemblée de Lisbonne, 1933, IATME Bull., 9, 238-240, 1934b.

Mitchell, A. C.: On the vertical force changed during the sudden commencement of a magnetic storm, Proc. Roy. Soc. Edinburgh, 45, 297-301, 1925.

Nagaoka, H.: Sudden commencement of magnetic storms and its probable cause, Proc. Imp. Acad., 17, 250-255, 1941.

Nagata, T. and Fukushima, N.: Chikyu Kansoku Hyakunen (One Hundred Years of Geophysical Observation), University of Tokyo Press, Tokyo, Japan, 329 pp., 1983.

Nippoldt, A.: Louis Agricola Bauer and terrestrial magnetism, Terr. Mag., 37, 205-208, 1932.

Ono, S.: Disturbance in the Magnetic Observations Caused by the Electric Works, Geophys. Mag. Tokyo, 3, 229-289, 1930.

Ono, S.: Chijiki kansoku narabini kankei jikou no kenkyu (study of geomagnetism and some related affairs), Hattori Houkoukai Jigyo Hokoku (Report of Hattori Houkoukai Foundation), 1, 6162, 1934a.

Ono, S.: Dai-ni-kai kyokuchi kansoku hompo kansoku no gaiyou houkoku (Overview of the domestic observations during the Second Polar Year), Report of Academic Association of Japan (Nihon Gakujutsu Kyokai Hokoku), 9, 147-151, 1934 b.

Ono, S.: Chijiki to chidenryu narabini sono oyo ni tsukite (I) (On geomagnetism and earth current, and their applications), Journal of Physics College of Tokyo (Tokyo Butsuri Gakko Zasshi), 543, 87-91, 1937.
Rodés, L. S. J. R.: On the non-simultaneity of magnetic storms, Terr. Mag., 27, 161-166, 1922.

Ronalds, F.: On photographic self-registering meteorological and magnetical instruments, Abs. Paper. Comm. Roy. Soc. London, 5, 662-663, 1843.

Ronalds, F.: On photographic self-registering meteorological and magnetical instruments, Philos. T. R. Soc. Lond., 137, 111-117, 1847.

Stauning, P.: Auroral and geomagnetic research in Denmark, WDCC2 for Geomagnetism Kyoto News (Chijiki Sekai Shiryou Kaiseki Senta News), 64, 2-4, 2000.

Tanakadate, A.: A magnetic survey of Japan reduced to the epoch 1895.0 and the sea level carried out by order of the Earthquake Investigation Committee, The journal of the College of Science, Imperial University of Tokyo, Japan (Tokyo Teikoku Daigaku Kiyou, Rika), 44, 1-180 App. 1-346, 1904.

Tanakadate, A.: Preliminary report on sudden commencements of magnetic storms, Section Terr. Mag. Elect., Internat. Geod. Geophys. Union, Bull., Washington, D.C., 20-21, 1926.

Tanakadate, A.: Short preliminary report on three sudden commencements of magnetic storms, Comptes Rendus de l'Assemblée d'Association de Magnétisme et Electricité à Lisbonne, IATME Bull., 9, 149-157, 1934.

Tanakadate, A. and Bauer, L. A.: The earth's resudual magnetic field, Terr. Mag., 13, 67-71, 1908.

Terada, T.: On rapid periodic variation of terrestrial magnetism, The journal of the College of Science, Imperial University of Tokyo, Japan (Tokyo Teikoku Daigaku Kiyou, Rika), 37, 1-85, 1917.

Terada, T.: Diary of January 7 of the year 1921, in: Terada Torahiko Zenshu (the complete works of Torahiko Terada Vol. 14, Iwanami Shoten Publishers, Tokyo, Japan, 1998) 1921.

van Bemmelen, W.: On Magnetic Disturbances as recorded at Batavia, Proceedings of the Royal Netherlands Academy of Arts and Sciences, 9, 266-278, 1906.

van Dijk, G.: Time accuracy in magnetic registration, Nature, 86, 44, 1911. 